\title{
Behaviour of stainless and high strength steel bolt assemblies at elevated temperatures - a review
}

\author{
Mohamed A. Shaheen ${ }^{\mathrm{a}}$, Andrew S. J. Foster ${ }^{\mathrm{a}, *}$, Lee S. Cunningham ${ }^{\mathrm{a}}$, Sheida Afshan ${ }^{\mathrm{b}}$ \\ ${ }^{a}$ School of Mechanical, Aerospace and Civil Engineering, The University of Manchester, Manchester, UK \\ ${ }^{b}$ Department of Civil \& Environmental Engineering, The University of Southampton, Southampton, UK
}

\begin{abstract}
This study documents important aspects of bolt assembly performance in structural steel connections at elevated temperatures that have not been the subject of detailed investigation to date. The codified strength reduction factors listed in the European and US standards are evaluated against experimental results obtained from the literature. It is concluded that the codified reduction factors should be updated as they are in many cases found to be non-conservative, particularly in the high temperature ranges. The effect of fire on the microstructure of steel bolts is also discussed, providing an insight into the roles that phase transformation and metallurgical failure play in the performance of high strength and stainless steel bolt assemblies at elevated temperatures. The study concludes by proposing a new reduction factor equation, based upon experimental results found in the literature.
\end{abstract}

Keywords: Bolts, Connections, Fire, Reduction factor, Robustness, Stripping, Necking, Phase transformation, Metallurgical failure, Eurocodes, US codes, Stainless steel, High-strength steel.

\footnotetext{
${ }^{*}$ Corresponding author

Email address: andrew.s.j.foster@manchester.ac.uk (Andrew S. J. Foster)
} 


\section{Introduction}

This study reviews important aspects of bolt assembly performance in structural steel connections at elevated temperatures that have not been the subject of detailed investigation to date. These are summarized in Table 1. Bolt assemblies are defined as a load bearing system comprising both the nut and the bolt. Prior to 1995, EN 1993 1-2 [1] deemed it unnecessary to assess the behaviour of steel joints under fire conditions due to increased thermal mass of the joint area relative to that of incoming structural members, which heat faster because they have a relatively large exposed area compared with the cross-section. However, observations from full-scale fire tests have subsequently shown that steel connections occasionally fail at elevated temperatures, particularly their tensile components $[2,3]$. At ambient temperatures, there exists a substantial body of research, with studies focusing on specific aspects of bolt assembly performance (e.g. friction between mating threads, nut tolerance class, number of threads in the grip, pretension force, etc.), leading to accepted and broadly consistent provisions in international design regulations. At elevated temperatures the picture is substantially less complete and generally lacking in consistency, with many of these parameters remaining unevaluated, particular as far as the behaviour of bolt assemblies is concerned.

Bolts are critical components in structural steel connections that effectively govern their performance, particularly at elevated temperatures where robustness becomes an important factor. In such conditions, selecting an appropriate bolt is not an easy task as factors such as the degree of corrosion, the influence of fatigue and initial pre-load all contribute towards the temperature-dependent mechanical deterioration of the bolt assembly in a complex manner [4-6]. Design codes attempt to encapsulate the deterioration of bolt assemblies at elevated temperatures by means of so-called reduction factors, which give the ratio of the shear or tensile strength of the bolt assembly at elevated temperatures to their respective values at ambient temperatures. These are principally based upon experimental results and a limited number of numerical investigations [7-16]. At present however, there is no consensus on the exact conditions of the testing methods, nor the particularities of the numerical models 
employed and hence the reliability of the available reduction factors. A rational basis for the development of reliable reduction factors is particularly important in fire conditions where the connection must achieve the requisite strength and rotational capacity as well as permitting the development of secondary catenary forces in the incoming members.

Stainless steel is increasingly being used in routine structural design, aided in particular by the availability of supplementary design rules [21]. Bolts fabricated from stainless steel have many desirable characteristics that enable them to be exploited in a wide range of construction applications. Specifically, they posses inherent corrosion resistance and their ductility and fire performance, depending on the grade, can be superior to high strength bolts [15], providing a more robust structural connection in the accidental limit state. Notwithstanding these advantages, international regulations [22, 23] overlook the use of stainless steel bolts at elevated temperatures with the strength reduction factors for bolt assemblies being absent in their latest publications. Concurrently, stainless steel bolt assemblies have received very limited attention from the research community $[15,16,24]$; a similar narrative is also applicable to high-strength bolt assemblies at elevated temperatures.

To the authors' knowledge, no prior studies are available in the open literature regarding state-of-the-art of behaviour of stainless and high strength steel bolt assemblies exposed to fire. In the present study, particular consideration is given to bolt assembly mechanical properties, failure modes and their importance in defining the strength and ductility of structural connections. Particular attention will be given to high strength and austenitic stainless steel bolts, owing to their inherent mechanical advantages and the current absence of comprehensive incorporation into design codes. Table 2 summaries the major testing programmes conducted to date for bolt assemblies for various test parameters, which will be frequently referenced across this article. It is noted that international regulations use different designations for steel bolts. European designations will be used hereafter, however, when a specific reference is being discussed, the designation of the reference will be adopted. Table 
Table 1: Comparison between selected test parameters at ambient and elevated temperatures.

\begin{tabular}{|c|c|}
\hline $\begin{array}{l}\text { Tested parameter at ambient tem- } \\
\text { perature during the last century }\end{array}$ & $\begin{array}{l}\text { Re-evaluation at elevated temperature during the } \\
\text { last two decades }\end{array}$ \\
\hline Bolt grade 10.9 & {$[8,12-14,17-19]$} \\
\hline Bolt grade 8.8 & {$[7,10-12,14,17,20]$} \\
\hline Bolt grade 5.6 & No studies were reported \\
\hline Bolt grade 4.6 & No studies were reported \\
\hline Stainless steel bolts & Only austenitic types were studied $[15,16]$ \\
\hline Fully-threaded bolts & {$[7]$} \\
\hline Type of thread: coarse and fine & All reported studies considered coarse types only \\
\hline $\begin{array}{l}\text { Nut styles: thin nuts, regular nuts and } \\
\text { high nuts }\end{array}$ & All reported studies considered regular nuts only \\
\hline Nut tolerance class & $6 \mathrm{~g} 6 \mathrm{AZ}$ by $[7,13] 6 \mathrm{~g} 6 \mathrm{H}$ by $[10] 8 \mathrm{~g} 7 \mathrm{H}$ by $[11] 8 \mathrm{~g} 7 \mathrm{H}$ by $[10]$ \\
\hline Nut dilation & $\begin{array}{l}\text { Implicitly included in the reported studies but there is no } \\
\text { clear conclusion }\end{array}$ \\
\hline Number of threads in the grip & No studies reported \\
\hline Relative strength between mating threads & {$[7,10]$} \\
\hline Friction between mating threads & $\begin{array}{l}\text { Implicitly included in the reported studies but there is no } \\
\text { clear conclusion }\end{array}$ \\
\hline Galvanization & {$[7,13,18]$} \\
\hline Lubrication & No studies reported \\
\hline Pretension & Fan et al. [8] \\
\hline Effect of washers & No studies reported \\
\hline Applied load (static or dynamic) & $\begin{array}{l}\text { All reported studies adopted low strain rate except }[7] \text { ex- } \\
\text { ploited high strain rate of } 0.02 \mathrm{~min}^{-1} \text {. }\end{array}$ \\
\hline Combined stress & Only one study [18] \\
\hline Temper temperature level & $\begin{array}{l}\text { Implicitly included in the reported studies but there is no } \\
\text { clear conclusion }\end{array}$ \\
\hline Chemical compositions & $\begin{array}{l}\text { Implicitly included in the reported studies but there is no } \\
\text { clear conclusion }\end{array}$ \\
\hline
\end{tabular}


3 summarizes the equivalent bolt designation according to European and US specifications. 


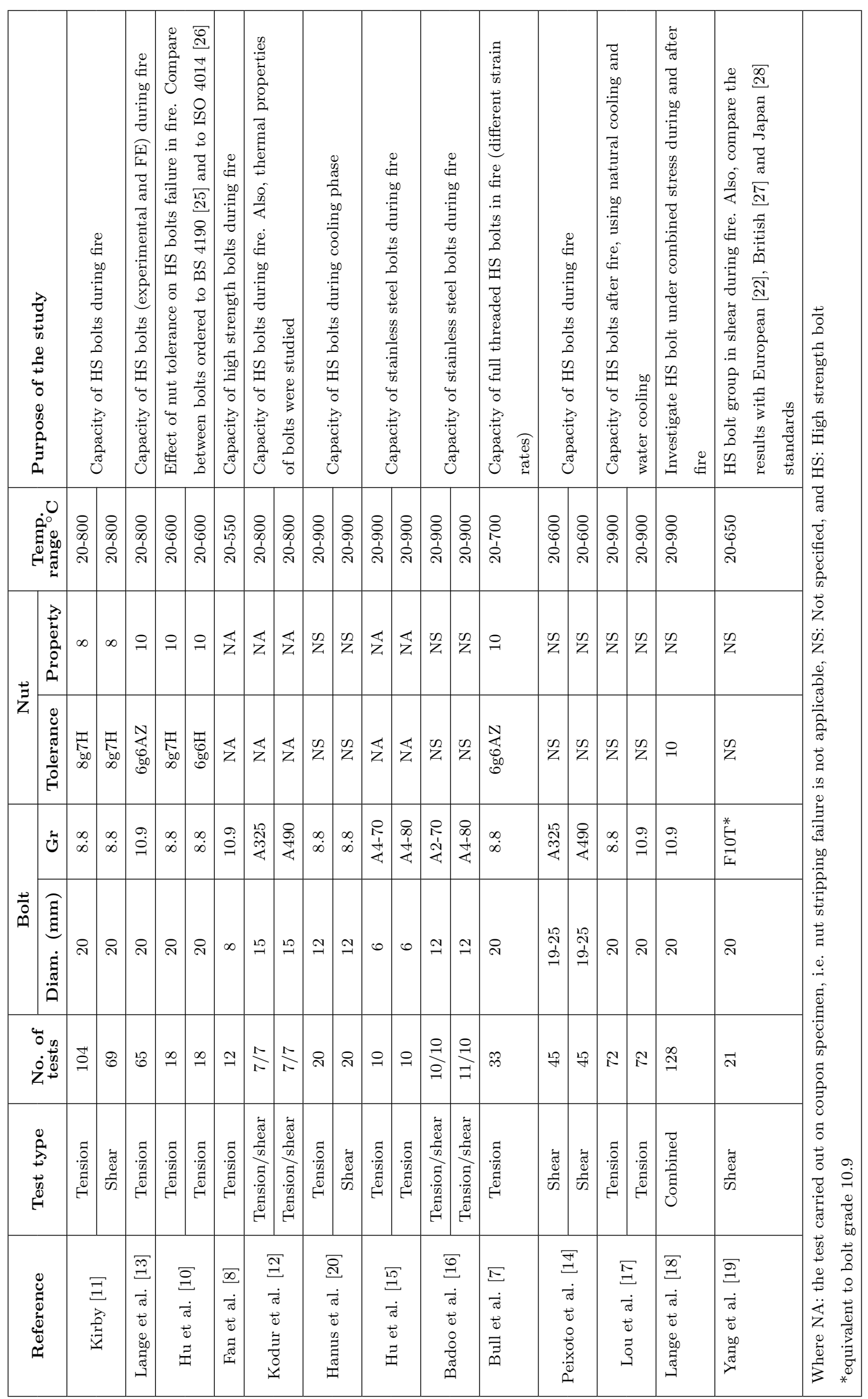


Table 3: Steel bolt designations and mechanical properties.

\begin{tabular}{|c|c|c|c|c|c|c|c|}
\hline Standarad & \multicolumn{3}{|c|}{ High strength bolt } & \multicolumn{4}{|c|}{ Austenitic Stainless steel bolt } \\
\hline Europe [29, 30] & Gr 8.8 & Gr 10.9 & A1 & A2 & A3 & A4 & A5 \\
\hline US [31-33] & A325 & A490 & 303 & 304 & 321 & 316 & $316 \mathrm{Ti}$ \\
\hline Ultimate strength (MPa) & $800-830$ & 1040 & \multicolumn{5}{|c|}{$500-800$} \\
\hline Yield strength (MPa) & $640-660$ & 940 & \multicolumn{5}{|c|}{$210-600$} \\
\hline Minimum elongation & $12 \%$ & $9 \%$ & \multicolumn{4}{|c}{$0.6-0.3$ of diameter } \\
\hline
\end{tabular}

\section{Bolt standards}

Since the publication of the current design guidance [22, 23], a wide range of additional experimental studies have been conducted on bolt assemblies, with a particular focus on new chemical compositions and observed failure modes. Thus, it is becoming important to consider these developments as part of a review of the current codes of practice. Carbon and alloy bolts in Europe and UK are delivered based on BS EN ISO 898-1 and BS EN ISO 4014 $[26,30]$ and additionally BS $4190[25]$ in the UK only. These specifications cover the full range of bolt grades from 4.6 to 10.9 for non-preloaded carbon and alloy bolts. Stainless steel bolts are manufactured to BS EN ISO 3506-1 [29] which covers the chemical and mechanical properties of austenitic, martensitic and ferritic types. In the US, specifications for chemical and mechanical properties of high strength bolts are covered by ASTM A325 and ASTM A490 [31, 32] while stainless steel bolts are covered by ASTM F593 [33].

Specifications covering chemical composition and mechancial properties at elevated temperatures for semi-finished bars and rods are provided by European Standard BS EN 10269 [34]. The requirements of this standard may be applied to finished bolts, however, subsequent treatments must also be considered before extrapolating values. For example, the specification lists the tensile strength of annealed stainless steel rods at elevated temperatures, however, cold-working is used for increasing tensile strength of some types of stainless steel bolts resulting in a change in microstructure that will inevitably affect their response to fire. 
In the US, ASTM A-193 [35] provides similar information for stainless steel bolts for high temperature services. Also, BS EN 1515-1 [36] is intended for bolting of pressurised pipe flanges (not beam or column flanges) and their joints, however it provides useful information for selection of bolts at elevated temperatures.

European and US standards [22, 23] employ temperature-dependent strength reduction factors for high strength bolts derived from a curve fitted to experimental data from tests carried out by Kirby [11]. However, there is some debate on the reliability of the codified reduction factors as some publications report that the current reduction values in the codes are not always conservative when used for other bolt types [12,37]. The curve fitting method is therefore only strictly valid for bolts similar to those used to produce the curve and thus, a wide range of tests considering various parameters and failure modes is necessarily required before extrapolating to other bolts. Table 4 compares the codified strength reduction factor deviations from the lowest value recorded in the literature, based on experimental studies presented in Table 2, concluding that the codified values are not conservative at high temperatures. 
Table 4: Deviation of codified reduction values from the tests for high strength bolts.

\begin{tabular}{|c|c|c|c|}
\hline \multicolumn{4}{|c|}{ Deviation from tests \% } \\
\hline Temp. ${ }^{\circ} \mathbf{C}$ & EN 1993-1-2 [22] & AISC $[\mathbf{2 3}]$ & Ref. for the lowest value \\
\hline 20 & -2 & -2 & Hu et al. $2007[10]$ \\
\hline 100 & -5.38 & -5.16 & Kirby 1995 [11] \\
\hline 200 & -2.68 & -3.23 & Kirby 1995 [11] \\
\hline 300 & -6.32 & -7.87 & Wang 2005 [38] \\
\hline 400 & +1.93 & -0.93 & Hu et al. $2007[10]$ \\
\hline 500 & +25.45 & +23.5 & Kodur et al. $[12]$ \\
\hline 600 & +31.81 & +45.45 & Kodur et al. $[12]$ \\
\hline 700 & +30 & +41.42 & Kodur et al. $[12]$ \\
\hline 800 & +25.37 & +21.13 & Kodur et al. $[12]$ \\
\hline where: $(-)$ On the safe side and (+) On the unsafe side. \\
\hline
\end{tabular}

\section{Bolt assembly failure modes}

The ability of flexural structural elements to develop cateneray action is important for their survivability at elevated temperatures and is governed by the rotational capacity and strength of the connections [39-42]. Investigations carried out on different connection configurations [43-45] showed that the connection failure temperature can be increased by avoiding the premature failure of the bolts. The main bolt failure modes are necking, stripping, shear and metallurgical, an overview of which is described hereafter.

\subsection{Failure modes due to applied tension forces}

Fig. 1 illustrates the different failure modes of a bolt assembly under tension. There are primarily two tensile failure modes at elevated temperatures: necking failure and stripping failure. The former is a ductile failure mode due to substantial plastic deformation in the bolt shank typically in the threaded part. Stripping failure occurs when the engaged threads experience large shear deformations that eventually result in the nut disengaging. Stripping 
failure is essentially a shear failure and often occurs in a brittle mode [46]. Necking failure is preferred in engineering practice and recommended by [47] as it provides a ductile connection with appreciable rotational capacity.

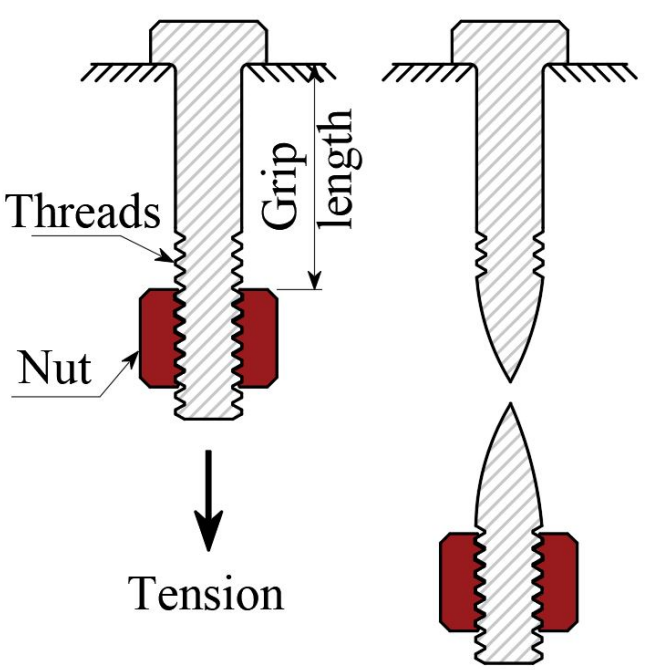

(a) (b)

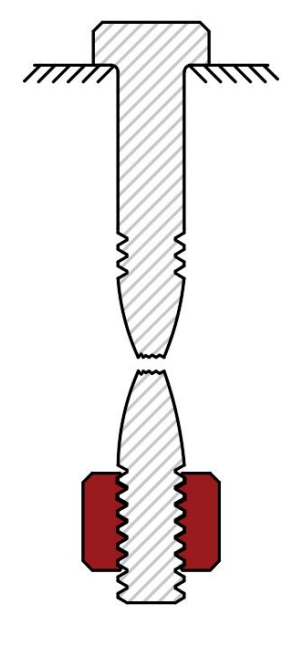

(c)

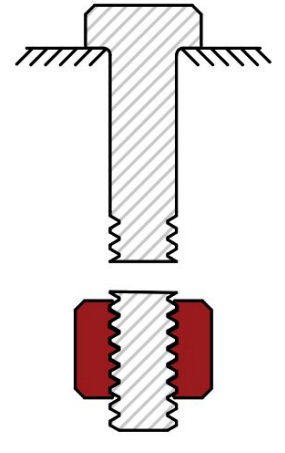

(d)

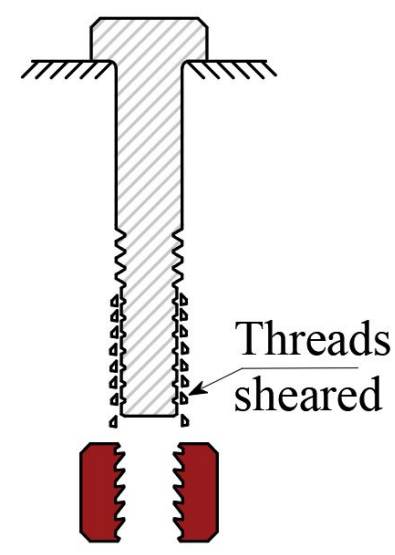

(e)

Figure 1: Bolt failures under tensile force: (a) terminology; (b) high ductility; (c) moderate ductility; (d) brittle fracture; (e) stripping failure.

Two types of bolts are available in engineering practice: partially-threaded and fully-threaded. The former type has a grip length below the bolt head free of threads while the latter has threads that run from just under the head all the way to the tip. Stripping failure results in the complete loss of bolt tensile strength $[11,16]$, thus certain precautions should be considered to reduce the likelihood of this mode of failure. For partially-threaded bolts this can be achieved by using a nut with tighter tolerance class [11] or a nut with higher class property [10]. Additionally, the strengths of the bolt and the nut threads should be similar as it is shown that differences can result in the stripping of low strength threads [46]. For fully-threaded bolts, stripping failure is highly likely to occur even with these precautions [7]. Further studies are required to investigate why fully-threaded bolts seem to fail by stripping at elevated temperatures. 
The effect of thread length on both bolt strength and failure mode at ambient temperatures was investigated by Fransplass et al. [48] and Grimsmo et al. [49, 50]. They conclude that the number of threads within the grip length (see Fig. 1a) has a pronounced effect on the ductility of the response whilst the tensile strength was only slightly changed. By reducing the number of threads within the grip, necking may occur at the engaged threads, which reduces the thread overlap and hence increases the probability of stripping failure. The correlation between number of threads in the grip and the stripping failure is still likely to be valid for the bolt behaviour at elevated temperature, but remains uninvestigated.

The use of coatings, such as zinc, are essential for protecting high strength bolts in corrosive environments, such as offshore installations. Such coatings and finishes can lower the coefficient of friction between mating threads at elevated temperatures, increasing the propensity of a stripping failure [46]. Experiments conducted on high strength bolt assemblies with galvanized and non galvanised finishes are summarised in Table 5, with stripping failure occurring for galvanised specimens. This is due to the protective coatings having a lower melting point than the parent material of the bolts. A common coating is zinc which melts completely at $420^{\circ} \mathrm{C}$. As such, the use of coated bolts at temperatures exceeding half the melting point of the coating is not recommended [35]. It is also noted that molten coatings are a primary cause of liquid metal embrittlement (see section 3.3). One feasible solution is to use material that has inherent-corrosion resistant characteristics such as stainless steel.

\subsection{Failure modes due to applied shearing forces}

Failure of shear connections at elevated temperatures can occur in various ways including the shear failure of the bolts, bearing failure of the plate against the bolts, and rupture of the plates. Whilst the details of plate bearing and rupture failures at elevated temperatures are reported in many studies [51-53], this paper will focus on the shear failure of bolts rather than plate failures. Shearing forces typically result in brittle failure modes at ambient 
Table 5: Effect of nut coatings on observed failure modes.

\begin{tabular}{|l|l|l|l|l|l|}
\hline References & Bolt finish & Nut finish & $\begin{array}{l}\text { Property } \\
\text { class }\end{array}$ & $\begin{array}{l}\text { Tolerance } \\
\text { class }\end{array}$ & Failure \\
\hline \multirow{2}{*}{ Kirby [1]] } & - & - & 8 & Loose & Necking \\
\cline { 2 - 6 } & - & G & 8 & Loose & Stripping \\
\hline Bull et al. [7] & G & G & 10 & Tight & Stripping \\
\hline \multirow{2}{*}{ Hu et al. [37] } & - & - & 10 & Loose & Necking \\
\cline { 2 - 6 } & - & - & 10 & Tight & Necking* \\
\hline \multirow{2}{*}{ Hu et al. [37] (RT) } & - & G & 8 & Loose & Stripping \\
\cline { 2 - 6 } & - & G & 8 & Tight & Stripping \\
\hline $\begin{array}{l}\text { Where: (-) not galvanised, (G) galvanised, and (RT) test carried at room temperature } \\
\text { only. } \\
*\end{array}$ \\
*Two tests out of 36 failed by stripping. However, they achieved similar strength for \\
specimens which experienced necking failure.
\end{tabular}


temperatures, however in tests it has been observed that the ductility of shear connections increases at elevated temperatures [14]. Stripping failure is not commonly applicable in bolts subject to shear force due to the absence of tension. However in some shear tests [11], tension forces due to plate prying action have been observed. Thus, bolts under shear may experience considerable tensile forces depending on the connection configuration and flexibility of the connected plates, which can reduce the shear capacity of the bolt due to a combined stress effect.

\subsection{Metallurgical failure modes}

There are numerous metallurgical failure modes including corrosion (general, pitting and crevice), stress corrosion cracking, galvanic corrosion, liquid metal embrittlement, temper embrittlement, and hydrogen embrittlement. The latter three types are particularly affected by elevated temperatures and will be discussed in further detail.

Liquid metal embrittlement (LME) failure, as observed in a limited number of tests on high strength bolts by $[7,13,18]$, is due to the instability of platings and coatings at high temperatures. LME of galvanized steel bolts occurs when there is a simultaneous application of stress and high temperature. In this scenario, a surface layer of liquid zinc (Zn) is present. When a tensile stress sufficient to cause surface cracks is applied to a galvanised steel bolt, the liquid zinc flows into the crack tips, weakening the cohesion of grain boundaries, enabling the cracks to propagate easily into the steel matrix [54]. Accordingly, the bolt then fails instantly in a brittle manner [55].

Temper embrittlement (TE) is an intergranular failure caused by the reduction of the cohesion along grain boundaries, ultimately leading to a brittle failure mode (see Fig. 2b). It is a characteristic failure for alloy steels that are tempered or heated in the range of $375-575^{\circ} \mathrm{C}$ and then continuously cooled at a slow cooling rate. The susceptibility of bolts to fail by TE is also affected by the alloying elements. In particular, the most widely used alloying elements such as nickel, manganese, and chromium, enhance TE failure [55]. When bolts containing 
these alloying elements are exposed to elevated temperatures in this range and then continuously cooled, they may still be susceptible to brittle failure even if the bolt strength has not been affected. Thus despite it being well-documented in the literature that the ductility of the bolt increases with increasing temperature, TE shifts the ductile-to-brittle transition temperature to a significantly higher temperature [56], which can result in a brittle failure during a fire event.

High strength bolts are susceptible to failure by hydrogen embrittlement (HE). A source of hydrogen is required for $\mathrm{HE}$ to occur, which can be secured during the zinc electroplating process for galvanised high strength bolts or exposure to elevated temperatures in hydrogencontaining environments [56]. The tensile capacity and ductility of the high strength bolts significantly deteriorates due to the pressure exerted by the hydrogen bubbles that form on the metal grains (see Fig. 2c). The bubbles result in the formation of microcracks that grow and propagate with or without externally applied loads [57]. Eventually, the failure may be catastrophic and unpredictable, occuring anywhere between hours or years after the bolt was first fabricated [55]. HE failure was observed for grade 10.9 bolts in a petroleum structure [58], with the hydrogen being sourced to the galvanizing process.

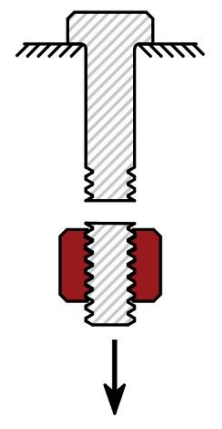

Tension

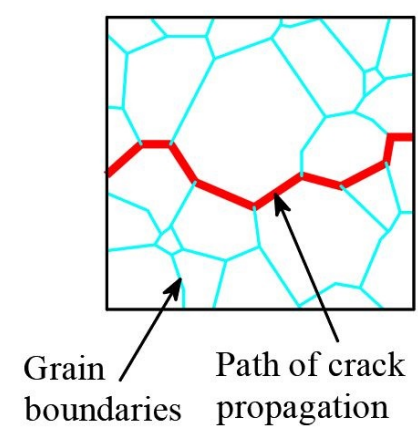

(a)

(b)
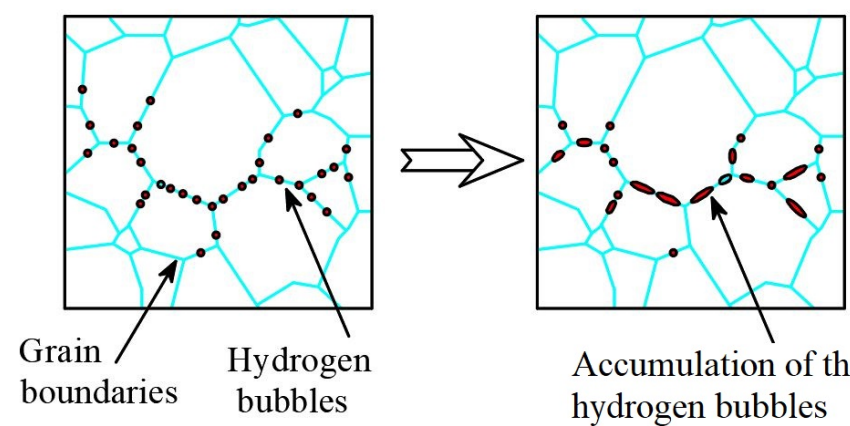

Accumulation of the hydrogen bubbles

(c)

Figure 2: Metallurgical failures: (a) intergranular failure (brittle fracture); (b) crack propagation along grain boundaries for intergranular fracture; (c) hydrogen bubbles along grain boundaries. 
It is clear from the discussion above that metallurgical failures of bolts occur due to the manufacturing processes of high strength bolts such as tempering and galvanization. Galvanization is not required for stainless steel bolts due to their inherent-corrosion resistance. Thus, stainless steel bolts, particularly austenitic types that are unaffected by heat treating processes, can be superior during a fire event.

\section{Fire effects on bolted connections}

\subsection{Fire models and thermal loading}

The damage to a steel bolted connection is largely controlled by how much heat is absorbed by its components. Predicting the extent of this thermal loading is challenging due to both the relative complexity of connection assemblies and the difficulties arising from modelling the heat source. The high thermal conductivity of steel ensures a high degree of heat transfer from the fire to the connection components. However, due to the relatively high mass concentration at the joint and the presences of gaps between plates, connection assemblies typically exhibit an uneven temperature distribution. Moreover, the fire location with respect to the connection is important for accurate thermal analysis, considering that the heat transfer is mainly radiative when the fire reaches its peak value [59].

The forces that develop in bolts during a fire depend on the type of connection and the fire phase (heating or cooling). Fig. 3 illustrates the typical forces on bolts during the heating and cooling phases for moment and shear beam-to-column connections. For moment connections, the tensile force in the bolts tends to reduce with increasing temperature due to the incoming beam undergoing expansion and exerting an opposing compressive force on the connection. For shear connections on the other hand, the force on the bolts tends to increase with the temperature [60], providing that the gap between the beam and the column flange is larger than the beam elongation during fire. Thus, the bolts in connections designed to carry only shear are more vulnerable to failure during the heating phase and before developing catenary action. In some scenarios, other factors such as the elongation of the bolt holes 
within the beam web [3] and an increase of the bolt ductility with temperature (section 3.2) may improve the connection shear behaviour.

If the fire is extinguished prior to any connection failure, the contraction of the steel beam during the cooling phase results in considerable tensile forces developing in the connection and the bolt $[60,61]$. It may argued that the full bolt strength is restored as the temperature decreases, based upon the incorrect assumption that the residual strength of high strength bolts is reversible as a result of cooling. However, the residual strength of high strength bolts depends upon various factors including the maximum attained temperature, the duration of the fire, and the cooling rate, all of which ultimately control the metallurgical phase transformation (see section 4.3). This frequently results in a significant reduction in bolt capacity even after the fire is extinguished. Thus, stable materials such as stainless steel are preferable in fire conditions and may eventually increase the beam survivability during the cooling phase (see section 4.3.2).

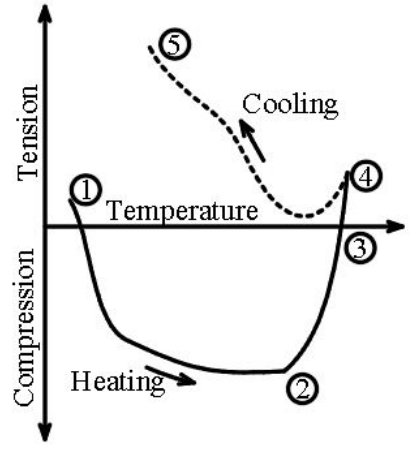

a) Typical axial-temperature response during and after fire.

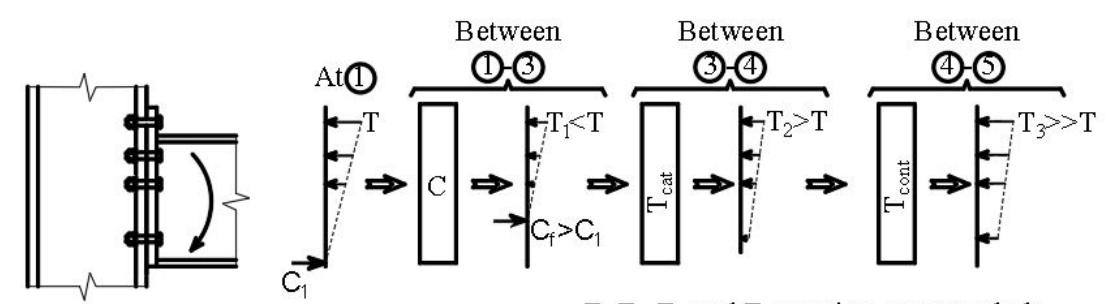

b) Bolt force during and after fire for moment connections.

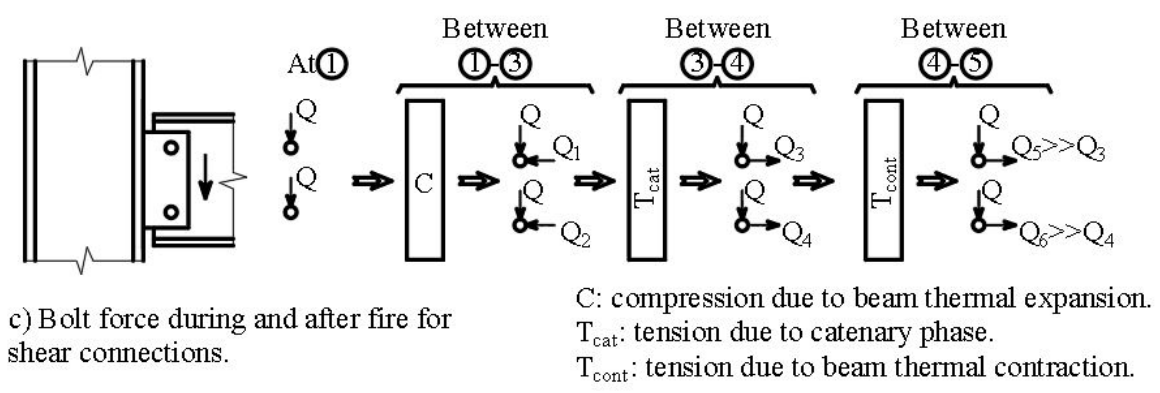

Figure 3: Bolt forces at elevated temperatures for moment and shear connections. 


\subsection{Effect of bolt failure on connection performance}

Experimental work carried out on moment-resisting beam-to-column connections showed that bolt stripping results in a premature failure of the connection, which significantly com-

promises its rotational capacity $[45,62]$. The rotational capacity of such connections can be improved by using a double nut configuration. In tests conducted by Yu et al.[63] a premature failure of the connection by bolt stripping failure was observed at a rotation of $1.5^{\circ}$. Using a double nut bolt configuration increased the rotation capacity to approximately $7^{\circ}$. For shear connections, researchers $[60,64,65]$ observed that the failure mode transitioned from plate bearing at ambient temperatures to bolt shear at elevated temperatures (beyond $500^{\circ} \mathrm{C}$ ). Santiago et al. [61] experimentally investigated six steel sub-frames with different connection configurations under natural fire conditions, using M20 Gr 8.8 and 10.9 bolts. It was reported that the failure mode changed from plate yielding during the heating phase to bolt stripping failure during the cooling phase.

\subsection{Effect of elevated temperatures on bolt strength from a material science prospective}

The mechanical properties of high strength steel bolts exposed to cycles of heating and cooling depend on the attained temperature and the cooling rate [66]. A schematic illustration of the phase transformation of high strength steel bolts when exposed to fire is depicted in Fig. 4 , based on [56]. Once the austenitic temperature $\left(\simeq 725^{\circ} \mathrm{C}\right)$ has been attained, the cooling rate is of primary importance as this affects the final microstructure of the material. When heating does not reach the austenitic temperature, tempered martensite results, causing an increase in the bolt ductility at the expense of its ultimate strength.

\subsubsection{Phase transformation of high strength bolts at elevated temperatures}

The microstructure of low alloy carbon steel at ambient temperature is pearlite, bainite or martensite, depending upon the rate of cooling of austenite steel. Bainite and pearlite transformations are competitive with each other and are stable phases. Thus whenever some portion of steel is transformed to either bainite or pearlite, it is not possible to transform 


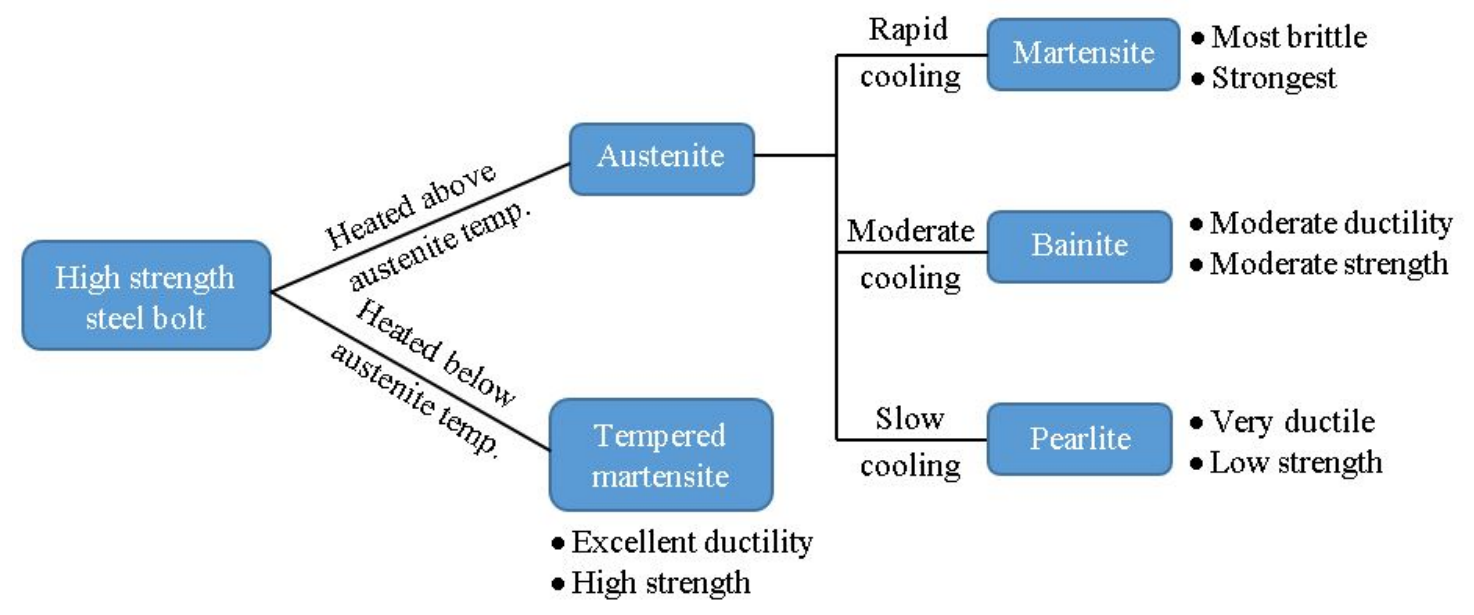

Figure 4: Effect of heating on steel bolt microstructure.

to other micro-constituents without reheating to form austenite. Martensite is formed when the austenite is rapidly cooled, or quenched, to a relatively low temperature in order to prevent carbon diffusion and hence the formation of pearlite or bainite. Martensite is not an equilibrium phase because the quenching process prevents diffusion of carbon out of the austenite structure. Thus it tends to transform to another structure when it is heated to a temperature (higher than $250^{\circ} \mathrm{C}$ ) that initiates diffusion of trapped carbon in the lattice [67].

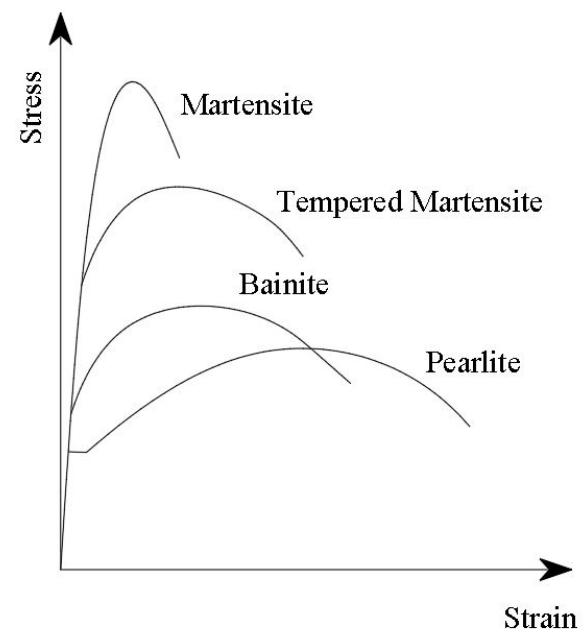

Figure 5: Schematic representation of the mechanical behaviour of different carbon steel microstructures. 
Fig. 5 schematically illustrates the mechanical behaviour of different carbon steel microstructures. Martensite is the hardest and strongest microstructure and the most brittle, thus it cannot be used for most structural engineering applications. However, heat treating martensite between $250^{\circ} \mathrm{C}$ and $650^{\circ} \mathrm{C}$ results in the formation of tempered martensite which possesses substantially enhanced ductility and formability without any significant compromises in strength. The increase in ductility in tempered martensite is attributed to the transformation of the single phase martensitic structure to stable ferrite and cementite phases [56]. This transformation takes place at temperatures exceeding aproximately $300^{\circ} \mathrm{C}$ [67]. Thus, when high strength bolts are heated below $300^{\circ} \mathrm{C}$, the tensile strength would theoretically remain unchanged. This has been confirmed by previous research $[9,11,13,37]$, all reporting that the reduction factor for high strength bolts is unity for temperatures below $300^{\circ} \mathrm{C}$. Above $350^{\circ} \mathrm{C}$, the cementite transformation is fully developed and growing with increasing temperature. Thus, the bolt strength reduction factor is controlled by the amount of developed cementite which is primarily a function of attained temperature and holding time. Other contributing parameters to the rate of cementite transformation include carbon weight and the presence of other additives.

\subsubsection{Phase transformation of austenitic stainless steel at elevated temperatures}

Austenite stainless steel bolts do not respond to quench-hardening treatment as their microstructure does not change with temperature [68]. This is one of the basic reasons for the stable microstructure of stainless steel at high temperatures; this is not observed for high strength steels. However, exposing austenitic stainless steel to fire at temperatures between $500^{\circ} \mathrm{C}$ and $850^{\circ} \mathrm{C}$ leads to formation of chromium-rich carbide $C_{23} C_{6}$ [67]. This precipitate has adverse effect on the mechanical properties, increasing the susceptibility of the material to intergranular corrosive attack. However, this can be ameliorated by reducing the carbon content or using strong carbide-formation elements such as titanium (as in austenitic A5 types) which react with carbon and form a carbide much more stable than $C_{23} C_{6}$. 


\subsubsection{Chemical composition of high strength bolt material}

Additives is added to the steel to retard ferrite formation during quenching process as well as secure transformations to martensite throughout the steel part even at lower cooling rates, which reduces residual stress and distortion during heat treatment. The degree of hardenability of carbon varies with the level of carbon and alloying elements. Treatment with boron has become quite popular with fabricators as it results in greater hardenability without using more expensive alloy steels [69]. Europe and US specifications provide three alternatives chemical composition requirements for a specific bolt grade, based on the additives used in the matrix. Chemical composition of boron treated carbon steels are listed in Table 6 comparing with the chemical composition of bolts tested in the literature, stainless steel bolt is not included in the table because of the limited available tests in the open literature. It is clear that the chemical composition significantly varies with the regulations and the suppliers which can result in high scatter of mechanical properties of bolts at elevated temperature. Further studies are required to investigate the effect of different element alloys on the bolt respond during fire. 


\begin{tabular}{|c|c|c|c|c|c|c|c|c|c|c|}
\hline & $>$ & $\frac{\pi}{z}$ & $\bar{z}$ & $\tilde{z}_{z}$ & $\pi_{2}$ & 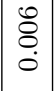 & $\begin{array}{l}0 \\
\dot{Q} \\
\dot{\vec{v}}\end{array}$ & & & I \\
\hline & $\ddot{F}$ & $\Omega^{2}$ & $Z_{Z}^{2}$ & $\begin{array}{l}2 \\
z\end{array}$ & $z_{z}^{2}$ & $\mid \begin{array}{l}0 \\
\mathscr{0} \\
0 \\
0\end{array}$ & $\begin{array}{l}\stackrel{T}{J} \\
\dot{0}\end{array}$ & & & $\begin{array}{l}\overrightarrow{0} \\
\dot{0}\end{array}$ \\
\hline & $\vec{Z}$ & $\pi_{2}^{2}$ & $Z_{z}^{2}$ & $\frac{\sigma}{z}$ & $z_{z}^{2}$ & $\mid \begin{array}{l}l \\
0 \\
0 \\
\dot{0} \\
\dot{v}\end{array}$ & $\mid \begin{array}{l}2 \\
0 \\
0 \\
\dot{0} \\
\vec{v}\end{array}$ & ' & & ' \\
\hline & $\mathrm{z}$ & $\frac{\pi}{z}$ & $Z_{Z}^{2}$ & $\begin{array}{l}\Omega \\
z\end{array}$ & $\frac{n}{z}$ & $\mid \begin{array}{l}\infty \\
0 \\
0 \\
0\end{array}$ & $\begin{array}{c}\tilde{J} \\
0 \\
0\end{array}$ & , & & ' \\
\hline & $\overrightarrow{0}$ & $z^{2}$ & 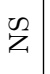 & $\tilde{z}_{z}$ & $\frac{n}{z}$ & $\mid \begin{array}{c}\underset{N}{N} \\
\stackrel{0}{0}\end{array}$ & $\begin{array}{c}+ \\
-1 \\
0\end{array}$ & 0 & $\mid \begin{array}{l}+ \\
0 \\
0\end{array}$ & $\begin{array}{l}\stackrel{8}{0} \\
\dot{0}\end{array}$ \\
\hline$\Delta^{\circ}$ & $\infty$ & $\begin{array}{l}\tilde{O} \\
\dot{0} \\
\dot{\nabla} \\
v\end{array}$ & $\begin{array}{l}\tilde{8} \\
\dot{\delta} \\
\dot{\nabla}\end{array}$ & $\left|\begin{array}{c}0 \\
0 \\
1 \\
1 \\
2 \\
\delta \\
0 \\
0 \\
0\end{array}\right|$ & \begin{tabular}{|l}
0 \\
0 \\
1 \\
1 \\
$\dot{0}$ \\
8 \\
0 \\
$\dot{0}$
\end{tabular} & $\mid \begin{array}{l}\overrightarrow{0} \\
\stackrel{8}{8} \\
\dot{0}\end{array}$ & $\begin{array}{l}\vec{N} \\
\tilde{\delta} \\
\dot{0}\end{array}$ & $\begin{array}{l}L \\
\stackrel{8}{0} \\
\dot{\varphi} \\
\mathrm{v}\end{array}$ & 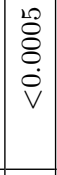 & $\begin{array}{l}\stackrel{\mathbb{S}}{\delta} \\
\dot{\delta} \\
\dot{0}\end{array}$ \\
\hline $\begin{array}{l}\stackrel{7}{*} \\
0 \\
0\end{array}$ & $\bar{\psi}$ & $\frac{\pi}{z}$ & $\frac{\pi}{Z}$ & $\frac{\pi}{z}$ & $\frac{n}{z}$ & \begin{tabular}{|l}
$\vec{Q}$ \\
$\dot{0}$ \\
$\dot{0}$
\end{tabular} & $\begin{array}{l}\mathcal{O} \\
\dot{\delta} \\
\dot{0}\end{array}$ & ' & , & $\begin{array}{l}\tilde{\delta} \\
\dot{0} \\
\dot{0}\end{array}$ \\
\hline$\left|\begin{array}{c}\tilde{0} \\
0 \\
\sigma\end{array}\right|$ & $\ddot{z}$ & $\frac{\pi}{z}$ & $Z_{Z}^{2}$ & $\begin{array}{l}2 \\
z\end{array}$ & $z_{z}^{2}$ & $\begin{array}{c}\underset{1}{1} \\
0 \\
0\end{array}$ & $\overrightarrow{0}$ & ' & & $\begin{array}{l}\stackrel{0}{0} \\
\stackrel{0}{0}\end{array}$ \\
\hline$\left|\begin{array}{c}\tilde{z} \\
\bar{d} \\
\bar{J}\end{array}\right|$ & $\stackrel{0}{\Sigma}$ & $\frac{\pi}{z}$ & $\bar{z}$ & $\frac{\pi}{z}$ & $\Sigma_{z}$ & 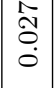 & $\begin{array}{l}\overrightarrow{\widehat{D}} \\
\dot{0}\end{array}$ & 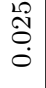 & $\stackrel{\sim}{o}$ & $\begin{array}{l}20 \\
8 \\
0 \\
0\end{array}$ \\
\hline & $\dot{U}$ & $z^{2}$ & Z & $\frac{\pi}{z}$ & $\Sigma_{z}$ & $\mid \begin{array}{l}\stackrel{2}{0} \\
\stackrel{0}{0}\end{array}$ & $\begin{array}{l}\Re \\
\stackrel{2}{0} \\
\vdots\end{array}$ & 0 & $\begin{array}{l}\mathcal{T} \\
0 \\
0\end{array}$ & 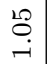 \\
\hline & $\boldsymbol{n}$ & $\begin{array}{l}20 \\
0 \\
0 \\
0 \\
V\end{array}$ & 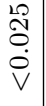 & $\begin{array}{l}2 \\
\stackrel{2}{0} \\
\dot{\vec{V}} \\
\mathrm{~V}\end{array}$ & $\begin{array}{l}\vec{\Delta} \\
\dot{\vec{v}}\end{array}$ & $\begin{array}{l}\pi \\
0 \\
0 \\
0\end{array}$ & $\begin{array}{l}0 \\
\dot{Q} \\
\dot{0}\end{array}$ & 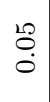 & $\begin{array}{l} \\
0 \\
0\end{array}$ & $\begin{array}{l}\text { ̊े } \\
\stackrel{0}{0}\end{array}$ \\
\hline & $a_{1}$ & $\begin{array}{l}\stackrel{L}{2} \\
\stackrel{0}{\dot{v}} \\
\dot{\nabla}\end{array}$ & 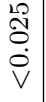 & $\begin{array}{c}\vec{D} \\
\dot{\dot{\theta}} \\
\mathrm{v}\end{array}$ & $\begin{array}{l}\vec{\Delta} \\
\dot{\vec{v}}\end{array}$ & $\begin{array}{l}\tilde{O} \\
\dot{0} \\
\dot{0}\end{array}$ & $\mid \begin{array}{c}2 \\
\stackrel{0}{0} \\
0\end{array}$ & $\begin{array}{l}\tilde{O} \\
\stackrel{0}{\circ}\end{array}$ & $\begin{array}{l}\ddot{D} \\
\dot{0}\end{array}$ & $\begin{array}{l}m \\
\stackrel{0}{0} \\
\dot{0}\end{array}$ \\
\hline & $\sum$ & $\begin{array}{l}0 \\
\dot{0} \\
\wedge\end{array}$ & $\begin{array}{l}\check{1} \\
0 \\
\wedge\end{array}$ & {$\left[\begin{array}{l}0 \\
0 \\
1 \\
1\end{array}\right]$} & 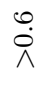 & $\mid \begin{array}{c}0 \\
-1 \\
-1\end{array}$ & 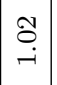 & $\stackrel{\circ}{\circ}$ & $\begin{array}{l}\infty \\
0 \\
0\end{array}$ & 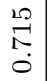 \\
\hline & $\ddot{\omega}$ & $\bar{z}^{2}$ & $\begin{array}{l}\Omega_{2} \\
Z\end{array}$ & $\mid \begin{array}{c}0 \\
0 \\
1 \\
1 \\
\dot{0} \\
0\end{array}$ & $\Sigma_{z}^{2}$ & $\begin{array}{l}\vec{\jmath} \\
0\end{array}$ & 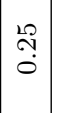 & $\stackrel{1}{\circ}$ & $\begin{array}{l}\tilde{y} \\
\tilde{O}\end{array}$ & $\begin{array}{l}20 \\
\stackrel{2}{0} \\
0\end{array}$ \\
\hline & 0 & 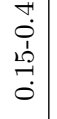 & 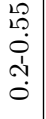 & $\mid \begin{array}{c}0 \\
1 \\
0 \\
0 \\
0 \\
0 \\
0 \\
0\end{array}$ & 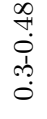 & $\stackrel{9}{\stackrel{9}{0}}$ & $\overrightarrow{\widehat{N}}$ & $\begin{array}{l}\stackrel{2}{N} \\
\stackrel{0}{0}\end{array}$ & \begin{tabular}{|c|c}
$\infty$ \\
$\dddot{0}$ \\
$ٌ$
\end{tabular} & 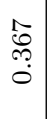 \\
\hline & 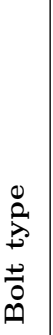 & 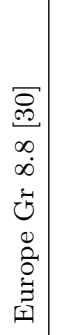 & 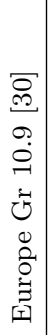 & 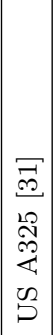 & 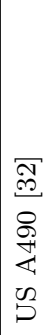 & 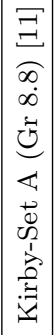 & 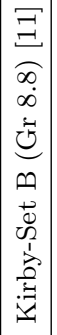 & 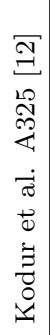 & 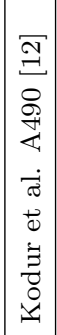 & 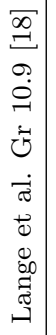 \\
\hline
\end{tabular}




\section{Experimental studies}

The absence of standard testing procedures for steel bolts is one of the main reasons behind the scattered results currently found in the literature. Fire testing includes many variables which may eventually have a profound effect on the results including the heating rate, soaking or holding time, cooling rate, type of fluid used for cooling, target or attained temperature, and the strain rate of the test. Table 7 summarises the test parameters investigated by different researchers. Each test parameter included in the table has a significant effect on the mechanical and material properties of the bolt. In particular, strain rate affects the ultimate strength and ductility of the bolt $[7,70]$, whilst the heating and holding times affect the material phase transformation $[69,71]$. The heating rate has a significant influence on the initiation of cementite. As illustrated by Fig. 7, the temperature at which this occurs increases with the heating rate [72]. A consequence of this is a higher nucleation rate and finer dispersion of cementite, leading to a reduction in bolt strength but higher ductility. The lack of consensus in testing methods is also apparent for arguably similar tests. This is apparent in Table 7 where for example Kirby [11] and Hu et al. [10] adopted a similar strain rate and holding time whilst the former used a smaller heating rate. This had a significant effect on the overall results of these studies, manifest in lower reduction factors as shown in Fig. 6. However, when the specimen is held at a higher temperature for a longer time, the effect of heating rate becomes smaller.

\subsection{Testing procedures}

There are primarily three types of fire testing procedures: steady state, transient state and natural fire (Fig. 8). The steady state method is a strain rate controlled procedure where the specimen is heated to a predetermined temperature at a specific heating rate and then loaded until failure. In this type of test, the obtained strain during the test is derived primarily from the applied stress. A holding phase is included to eliminate thermal strain; the creep strain can be neglected due to the short duration of the applied load. Steady state testing 
Table 7: Summary of test parameters and their ranges used in the literature.

\begin{tabular}{|c|c|c|c|c|}
\hline References & Test type & $\begin{array}{l}\text { Heating } \\
\text { rate } \\
{ }^{\circ} \mathrm{C} / \mathrm{min}\end{array}$ & $\begin{array}{l}\text { Holding } \\
\text { time } \\
\text { (mins) }\end{array}$ & Strain or loading rate \\
\hline Kirby [11] & Steady state & $5-10$ & 15 & $0.001-0.003 \mathrm{~min}^{-1}$ \\
\hline $\mathrm{Hu}$ et al. [10] & Steady state & 2.5 & 15 & $0.001-0.003 \mathrm{~min}^{-1}$ \\
\hline Kodur et al. [12] & Steady state & 5 & 15 & $150 \mathrm{kN} / \mathrm{min}$ \\
\hline Hu et al. [15] & Steady state & $50-80$ & 15 & $\begin{array}{l}0.03 \mathrm{~mm} / \mathrm{min} \text { until } \mathrm{F}_{\text {proof }} \\
0.75 \mathrm{~mm} / \mathrm{min} \text { after } \mathrm{F}_{\text {proof }}\end{array}$ \\
\hline Bull et al. [7] & Steady state & $1.5-3.8$ & No holding time & $0.002-0.02 \mathrm{~min}^{-1}$ \\
\hline Lange et al. [13] & Steady state & 10 & 30 & $\begin{array}{l}0.001 \mathrm{~min}^{-1} \text { until } 2 \% \mathrm{~F}_{\text {proof }} \\
0.025 \mathrm{~min}^{-1} \text { after } 2 \% \mathrm{~F}_{\text {proof }}\end{array}$ \\
\hline Fan et al. [8] & Steady state & 10 & 20 & $\begin{array}{c}0.5 \mathrm{~mm} / \mathrm{min} \text { before } 0.7 \mathrm{~F}_{\mathrm{u}} \\
2 \mathrm{~mm} / \mathrm{min} \text { after } 0.7 \mathrm{~F}_{\mathrm{u}}\end{array}$ \\
\hline Lou et al. [17] & Natural & 20 & 60 & $0.0015 \min ^{-1}$ \\
\hline Hanus et al. [20] & Natural & $10-30$ & 15 & Not mentioned \\
\hline Kodur et al. [73] & Natural & 10 & 15 & $0.02 \mathrm{~mm} / \mathrm{s}$ \\
\hline
\end{tabular}




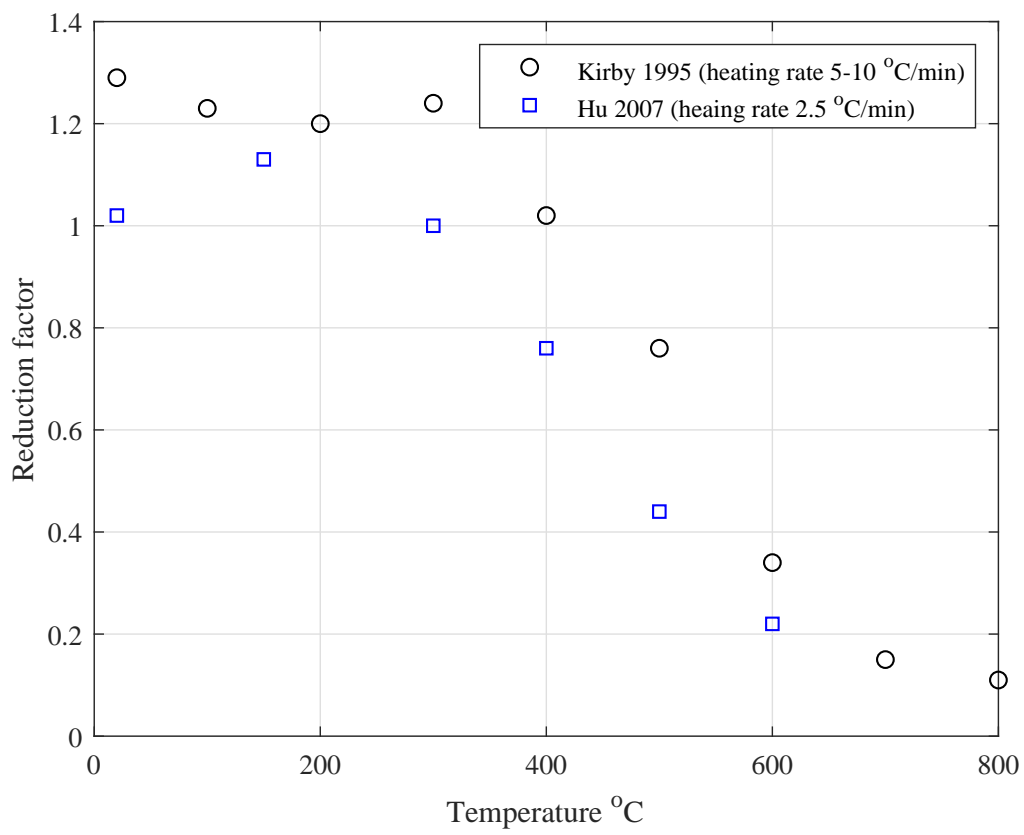

Figure 6: Effect of test parameters on bolt tensile strength reduction factors.

is commonly used as it directly provides the stress strain response at a specific temperature.

In the transient testing method, the specimen is positioned in the furnace and subjected to a predefined constant applied load while the temperature is linearly increased at a specific rate until failure. The transient state test attempts to simulate the real conditions of a tested component during a fire and can usually provide more realistic results. It should be noted that the final strain of the specimen tested in this type of test includes thermal strain, creep strain and stress related strain. As such, this type of test is commonly used when it is desired to study the creep of metal under temperature variation.

Lange and Gonzalez [13] conducted a comparative study of high strength grade 10.9 bolts subjected to transient and steady state testing conditions. It was found that the strains obtained by transient state tests were significantly higher than the steady state tests due to the creep strain. More generally, Qiang et al.[74] and Chen et al.[75] compared the results of the two test types by investigating high strength structural steel at elevated temperatures. 
In natural fire tests, both heating and cooling phases are considered (see Fig. 8). This test method can be used to evaluate the bolt residual strength during the cooling phase. There are many tests on high strength bolts found in the literature subjected to natural fire conditions $[17,20,73]$.

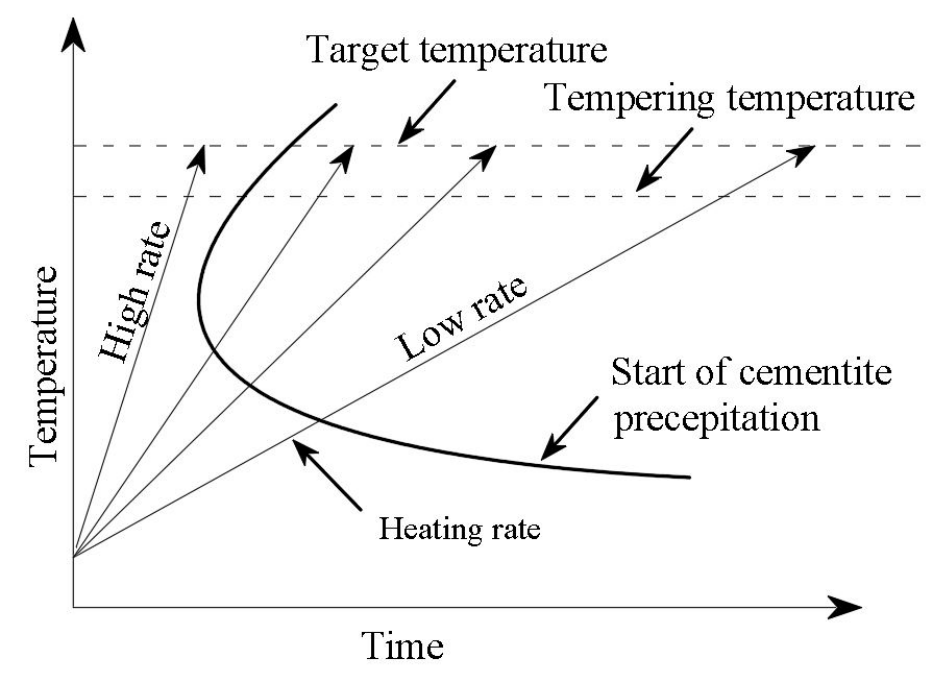

Figure 7: Schematic time-temperature-precipitation digram illustrating the effect of heating rate on cementite precipitation. 

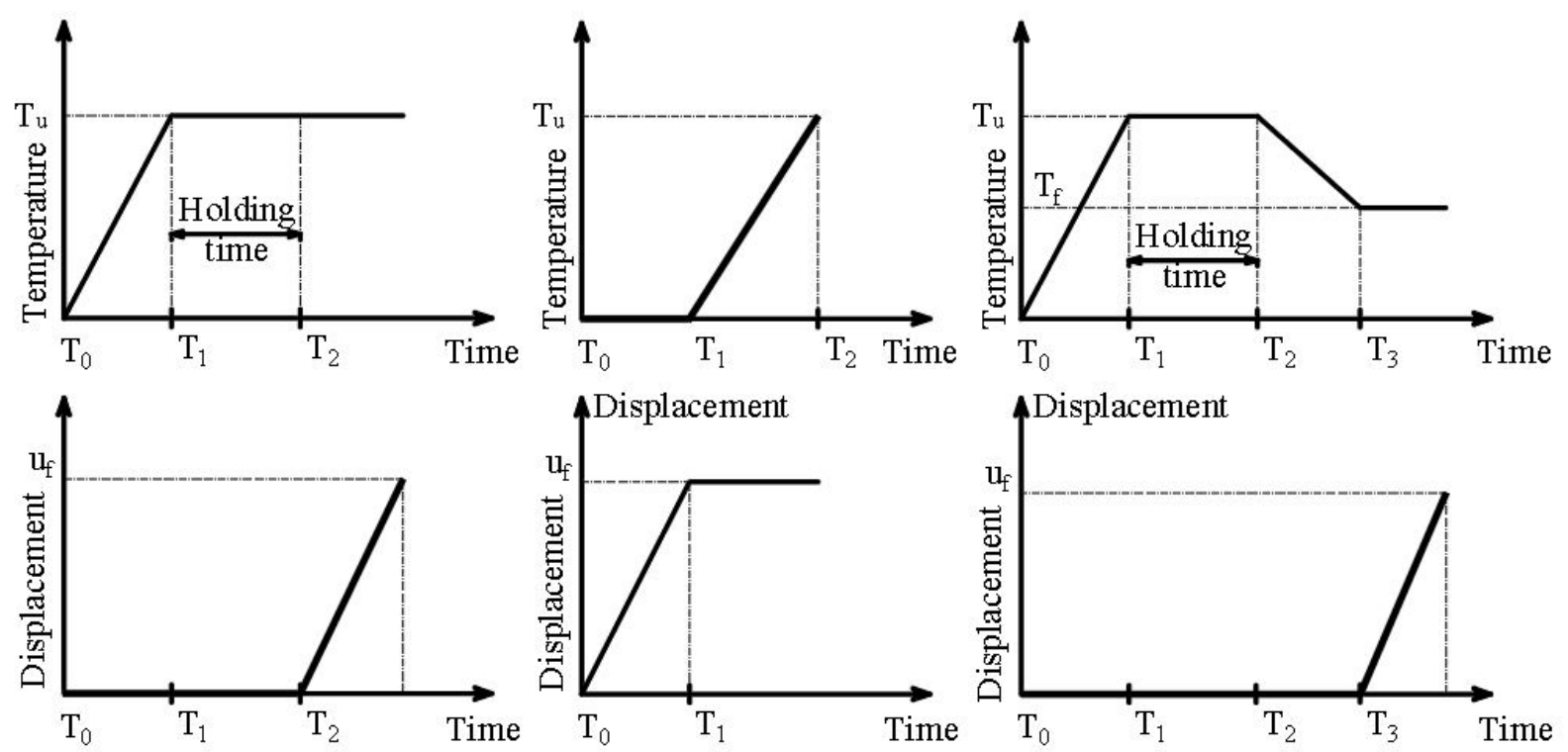

a) Steady state test

b) Transient state test

c) Natural fire test

$\mathrm{T}_{\mathrm{u}}$ : ultimate temperature.

$\mathrm{T}_{\mathrm{f}}$ : final temperature when appling the load.

$\mathrm{u}_{\mathrm{f}}$ : displacement at failure.

$\mathrm{T}_{0}-\mathrm{T}_{3}$ : time increment

Figure 8: Types of fire testing methods.

\section{Bolt strength reduction factors}

Generally, there are two analytical methods for predicting the capacity of structural components: the component-based method and the curve fitting method. The former method is widely used for predicting steel and steel-concrete composite connection behaviour [76, 77]. The latter method is used by researchers to predict bolt strength reduction factors at a specific temperature. The most widely used mathematical representations are trilinear or multilinear forms at different temperature intervals as shown in Fig. 9.

It is clear that the proposed fitted curves are somewhat different. As previously discussed, the response of the bolts and hence the strength reduction values are significantly influenced by the testing method, manufacturing process and chemical composition. These are all shown to vary between the studies in the open literature. It is therefore important to emphasise that the curves produced from this method should be limited to the bolts from 


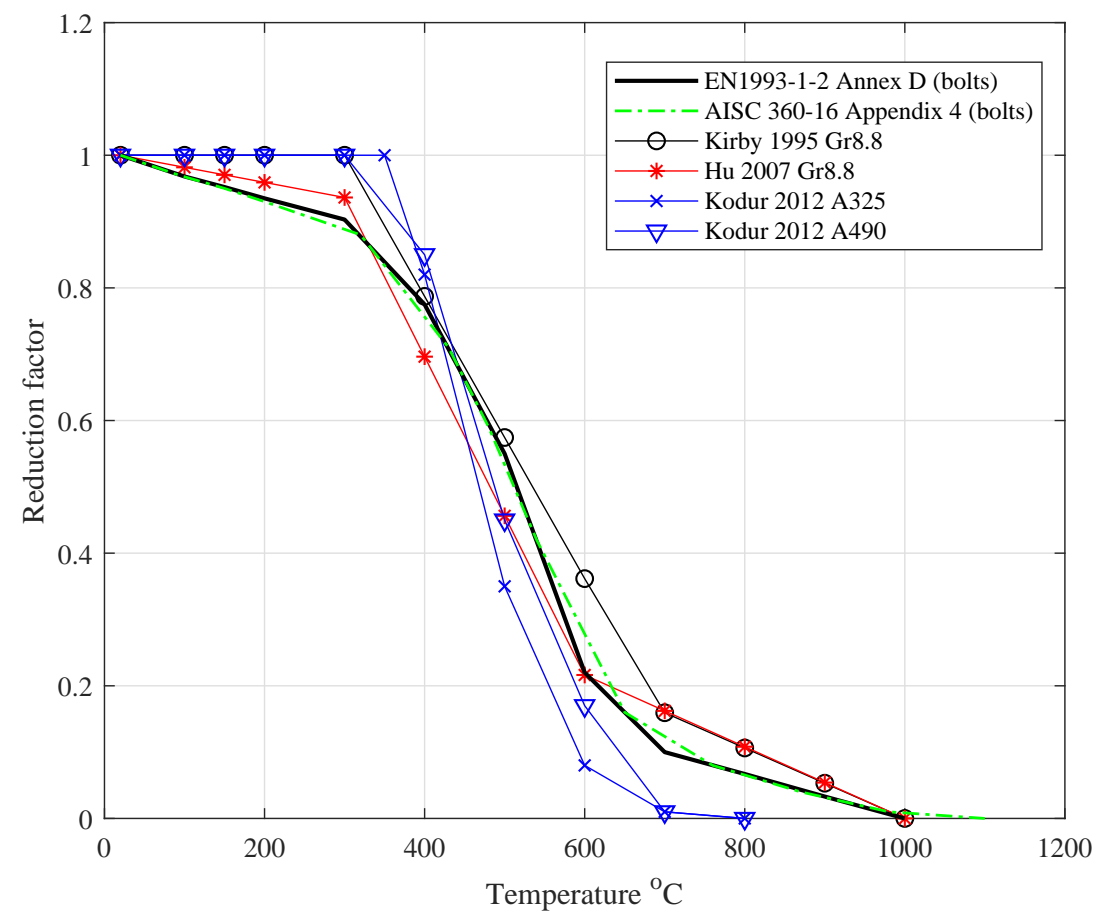

Figure 9: Plot of current tensile strength reduction factor equations in the literature.

which they are derived. For more general applications, a wide range of tests considering various parameters and failure modes is necessarily required before extrapolating to other bolts.

The behaviour of bolts at ambient temperatures has been thoroughly investigated for various parameters over the past century. However, connection behaviour at elevated temperatures only started to receive the attention of researchers from the mid-1990s. Table 1 summarises the investigated parameters that affect the bolt assemblies at ambient and elevated temperatures. It can clearly be seen that there are various parameters that have not been investigated at elevated temperatures, such as the number of threads in the grip and the use of washers. Other factors are implicitly included in tests at ambient temperatures such as friction between mating threads, chemical composition and tempering temperature level. However, there are no clear conclusions regarding their effect on bolt assembly behaviour at elevated temperatures. Also, fewer tests are observed that take into account the effects of combined 
stresses and pretension, which frequently occur in engineering practice. Accordingly, such parameters may cause real-world deviations from the codified values listed in international regulations $[22,23]$ that may not be on the safe side.

\subsection{Tensile strength of high strength bolts at elevated temperatures}

Published values for ultimate tensile strength of high-strength bolts at elevated temperatures normalised to the tension resistance based on EN 1993-1-8 [78] at ambient temperatures are presented in Fig. 10 as reduction factors, with all factors of safety set to unity. With reference to this figure, gradual losses in strength can be observed up to $300^{\circ} \mathrm{C}$, followed by a significant decrease in strength over the range $300^{\circ} \mathrm{C}$ to $600^{\circ} \mathrm{C}$. Beyond $600^{\circ} \mathrm{C}$, the austenitic phase transformation temperature, the strength becomes roughly independent of the manufacturing process and the testing methods. At approximately $500^{\circ} \mathrm{C}$, or at least slightly beyond the tempering temperature of $425^{\circ} \mathrm{C}$, the obtained test results show a very high degree of scatter, implying that strength reductions are influenced significantly by the testing methods, manufacturing processes and chemical composition.

To evaluate the conservatism of current reduction values in EN 1993-1-2 and AISC 360-16 $[22,23]$ for bolts, the codified reduction factors are plotted against experimental results collected from the literature in Fig. 10. The EN 1993-1-2 reduction factors for the ultimate tensile strength of mild steel is also depicted for purpose of comparison. Some experimental results report a lower strength than the codified reduction values for a given temperature, with the extent of the deviation depending upon parameters as diverse as the tolerance class of the nuts [37] or the supplier [12].

Fig. 10 shows that the EN 1993-1-2 mild steel reduction factors are higher than those measured for high strength steel bolts throughout the full temperature range, particularly beyond $400^{\circ} \mathrm{C}$. This because of mild steels attain their strength by forming pearlite, which is a stable structure that retains its strength at high temperatures, but overall these steels are characterized by low to moderate strength. On the other hand, high strength bolts 


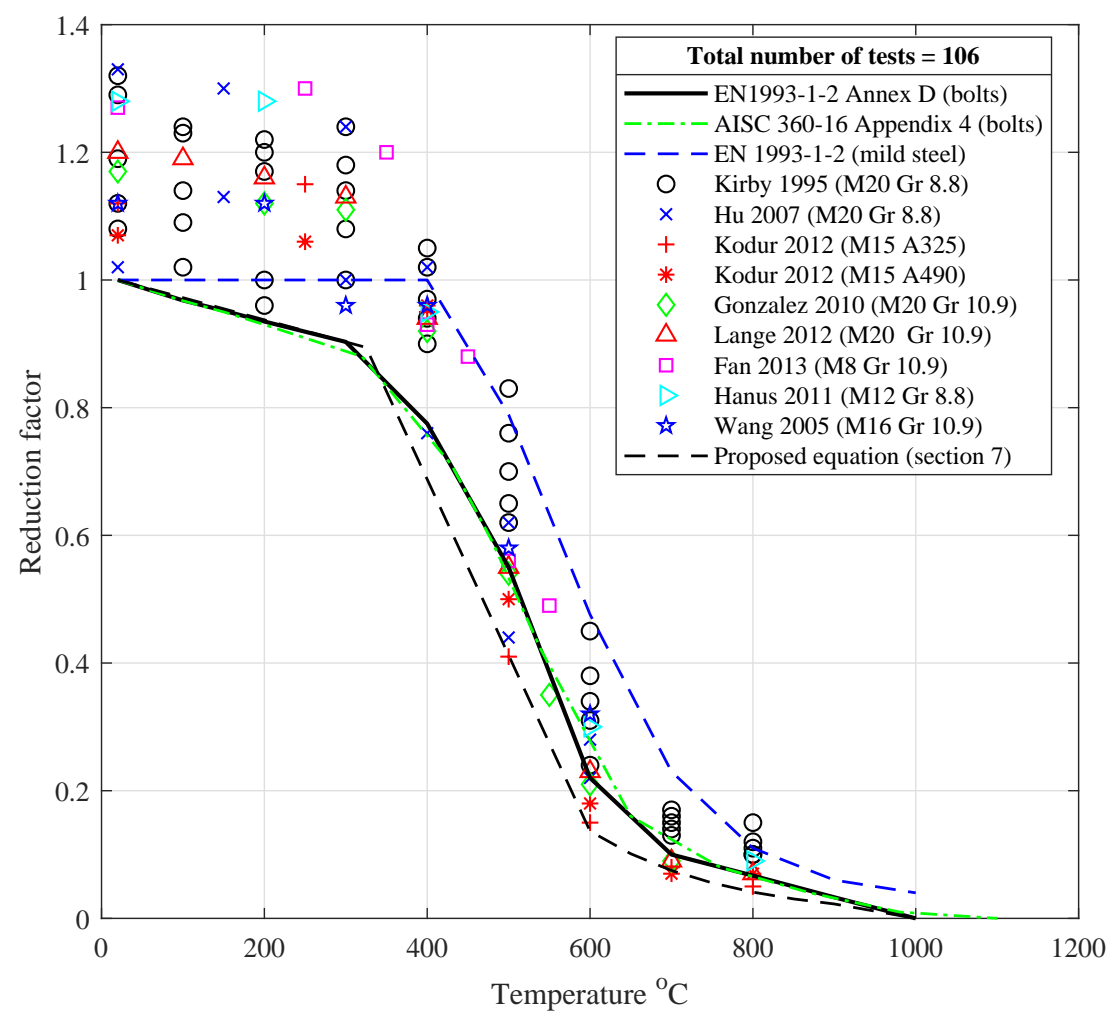

Figure 10: Reduction factors for the tensile strength of mild steel and high strength steel bolt assemblies at elevated temperatures.

attain their strength by cooling austenite very rapidly (see section 4.3) which results in a metastable and single-phase structure [56]. Thus it is potentially non-conservative to adopt the mild-steel steel reduction factors for high-strength bolts.

In general, bolt strength reduction factors are independent of the component diameter. With reference to Fig. 10, the results obtained by [20, 38] for M16 and M12 bolt diameters lie between the results of M20 bolts carried out by [11]. Along similar lines, the grade of the bolt is found to have a minor effect on the reduction factor. 


\subsection{Shear strength of high strength bolts at elevated temperatures}

Fig. 11 plots the reduction factors for bolt shear strength, derived by different researchers against the codified reduction factors in $[22,79]$. In constructing this figure, the test measured bolt shear capacities at elevated temperature are normalised by their respective shear resistances at ambient temperature calculated according to EN 1993-1-8 (Table 3.4) [78]. It is noted that the shear failure plane may pass through either the shank or the thread of the bolt. For the purposes of calculating the shear capacity, the net section was used for the shear area when the shear plane passes through either the shank or the thread of the bolt. Along similar lines to the tensile test results, published data for high strength bolts failing in shear at elevated temperatures exhibits a high degree of scatter, again a reflection of the absence of a consensus surrounding testing procedures under fire conditions. In general, the shear strength of the bolt deteriorates with increases in temperature. By comparing Fig. 10 and Fig. 11, it is clear that the codified shear strength reduction factors are more conservative when compared with the codified tensile strength, particularly in the low temperature range.

\subsection{High strength bolts subject to both combined stress and elevated temperatures}

A very limited number of tests have been conducted on bolts subject to combined tension and shear at elevated temperatures, with only one dataset currently available [18]. In the work by [18], the resulting combined stress reduction values lie between the test results for pure tension and pure shear. Notwithstanding these results, the number of the tests conducted is not enough to drive a reliable conclusion about the effect of combined stress on the bolt reduction factor during a fire.

\subsection{Post-fire capacity of high strength bolts}

The post-fire strength reduction factors for high strength steel bolts are summarised graphically in Fig. 12. The tensile strengths of the tested bolts reported in this figure were collected from the literature and normalised by the tension resistance at ambient temperature that calculated according to EN 1993-1-8 [78]. These results exhibit a very high degree 


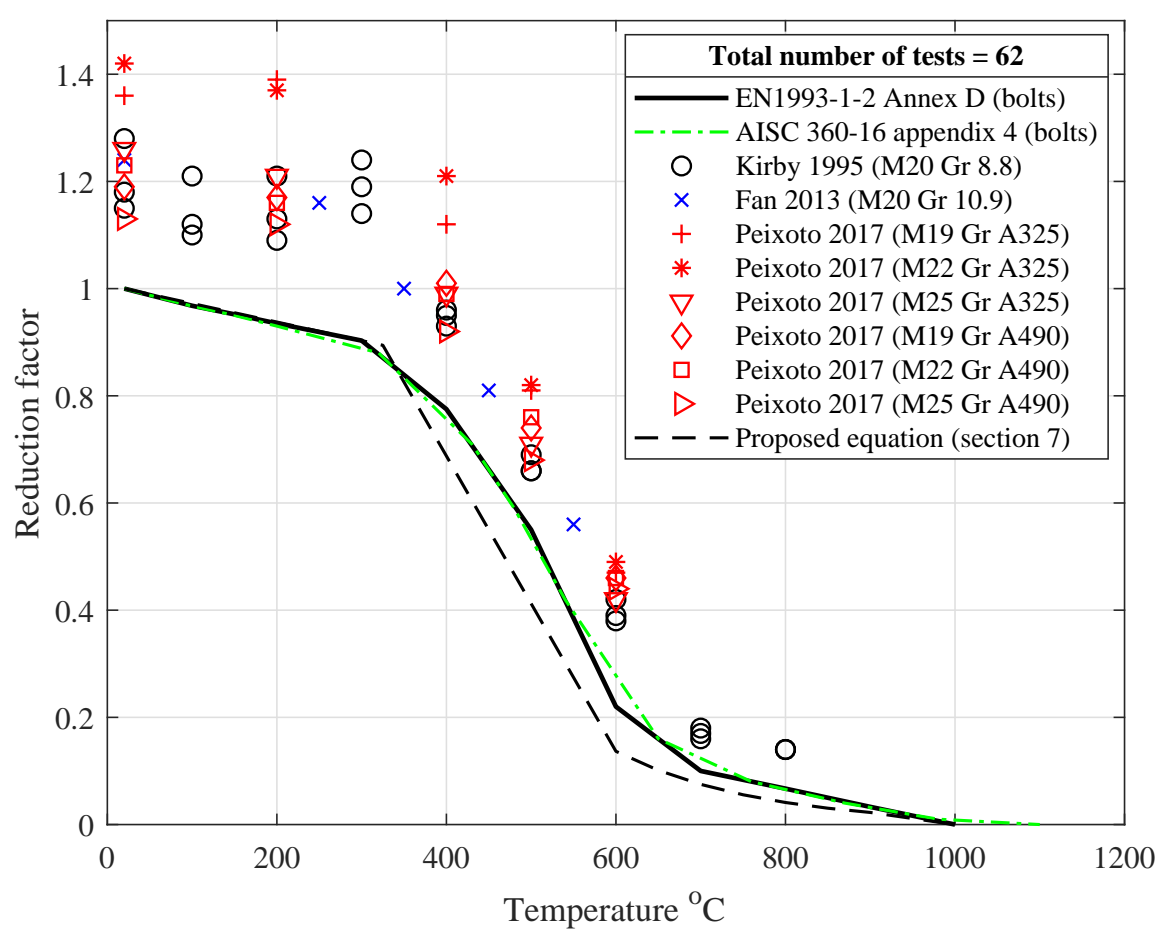

Figure 11: Shear strength reduction factors for high strength steel bolts at elevated temperatures.

of scatter over the reported temperature range, showing particular sensitivity to the cooling method. It is clear that the bolts retain much of their strength after cooling from an attained temperature not exceeding $300^{\circ} \mathrm{C}$. When the attained temperature exceeds $300^{\circ} \mathrm{C}$, the bolt generally loses a significant amount of its ultimate strength. However, using water to cool the bolt rapidly results in a strength higher than the bolt strength at ambient temperature, similar to the quenching process. For bolts heated beyond the austenite temperature (about $725^{\circ} \mathrm{C}$ ), the increased strength attained by rapid cooling comes at the expense of ductility.

Currently there are no post-fire reduction factors provided by either the Eurocodes or the AISC code; these reduction factors are solely based upon tests carried out on high strength steel bolts at elevated temperatures without considering the cooling phase. For comparison, Fig. 12 plots these codified reduction factor curves against the results obtained for post-fire residual strength tests. The normalised residual strength collected from experimental tests 


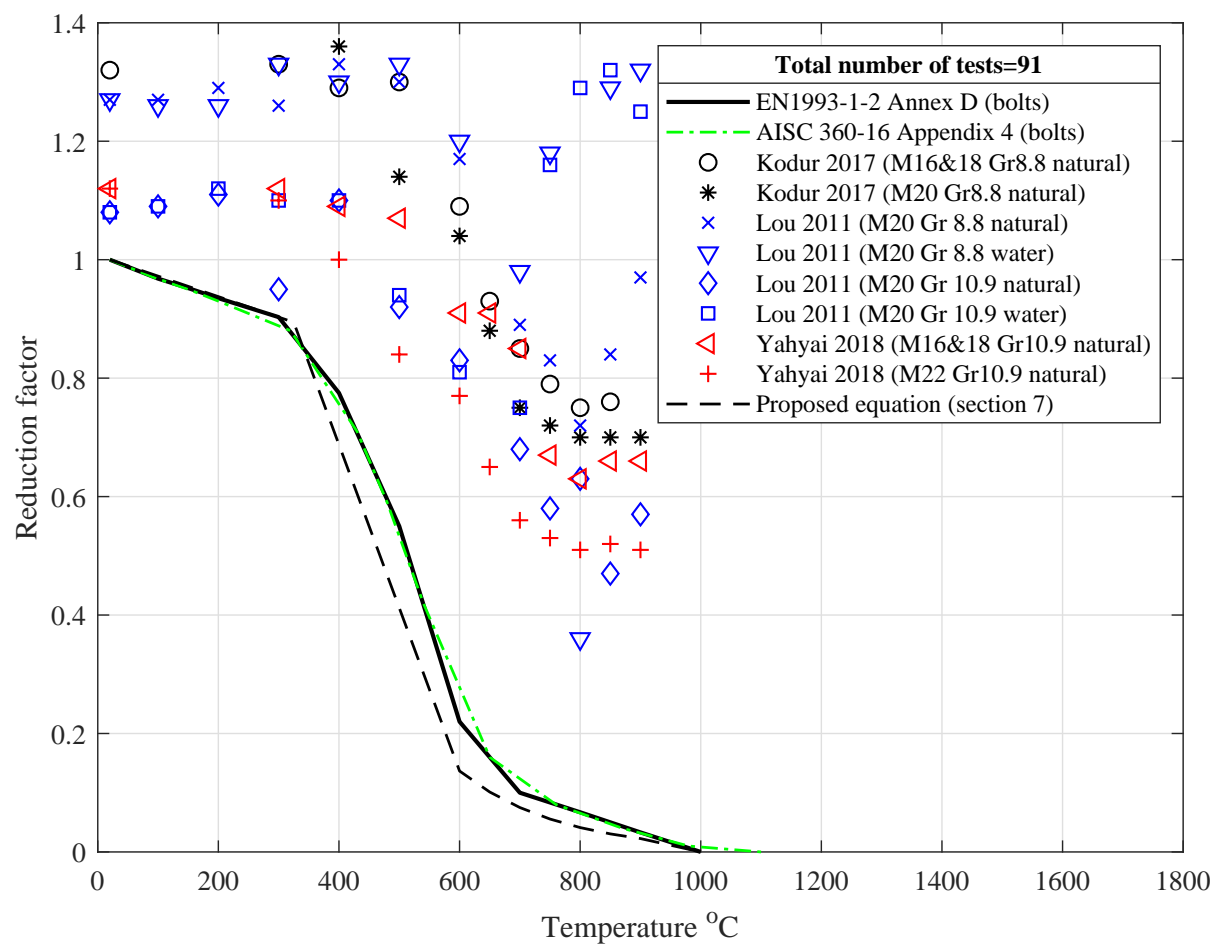

Figure 12: Post-fire strength reduction factors for high strength steel bolts in shear and tension.

lies above the codified curves indicating that the strength of the bolt during heating phase is more critical than the strength of the bolts after cooling.

\subsection{Strength reduction factors for stainless steel bolt assemblies at elevated temperatures}

Very few publications report on the behaviour of stainless steel bolt assemblies at elevated temperatures. Hu et al. [15] conducted a series of experimental tests on 60 stainless steel bolts (A4-70 and A4-80) at elevated temperatures $\left(20-900^{\circ} \mathrm{C}\right)$. The tests were carried out on coupon specimens prepared from the stainless steel bolts rather then full bolt assemblies. This approach neglects important bolt-nut interactions, including failure modes and friction between mating threads. Baddoo et al. [16] conducted tensile tests on stainless steel bolt types A2-70 and A4-80 over the temperature range $20^{\circ} \mathrm{C}$ to $900^{\circ} \mathrm{C}$. Unlike the $\mathrm{Hu}$ et al. tests, these tests were carried out on the bolt assemblies which account for different failure modes under tension. 


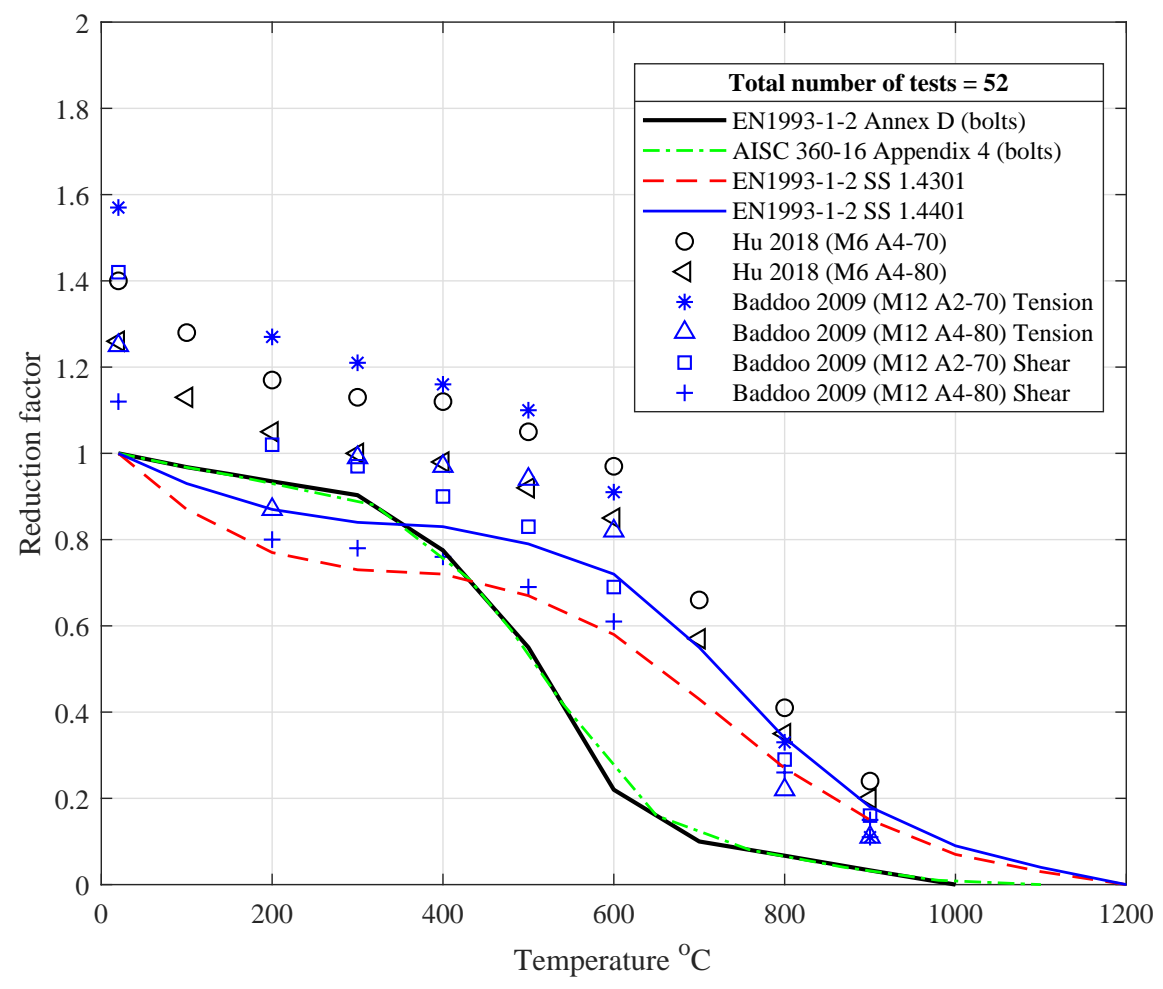

Figure 13: Tensile and shear strength reduction factors for stainless steel bolt assemblies at elevated temperatures.

Fig. 13 presents the tensile and shear tests results of $[15,16]$ normalised by the tension resistance at ambient temperature that calculated based on EN 1993-1-8 [78]. Additionally, the parent structural material reduction factors proposed by the Eurocodes for stainless steel types 1.4301 (equivalent to A2) and 1.4401 (equivalent to A4), in addition to high strength steel bolts are plotted in the figure for comparison. It is clear from the figure that stainless steel bolts possess better strength retention than high strength bolts at temperatures beyond $400^{\circ} \mathrm{C}$. At temperatures between $20^{\circ} \mathrm{C}$ and $400^{\circ} \mathrm{C}$, the tensile strength reduction factors for both bolt types are comparable while the shear strength of stainless steel types (A2 and A4) is inferior to the high strength bolts. Reduction factors for the stainless steel bolts and the equivalent parent material show a similar trend, however, the bolts exhibit a slightly 
higher reduction with the increase in temperature. Further, stainless steel bolts in shear are more sensitive to elevated temperatures than they are under tension. Overall, it must always be recognised that the reduction factors provided in all codes and standards are currently based upon very specific tests. A wide range of experimental tests encompassing the important parameters and failure modes discussed in this review is necessarily required before extrapolating to other bolts.

\section{Proposed strength reduction factor equation for bolt assemblies}

This study showed that the strength reduction factor for non-galvanised high strength bolts is primarily controlled by the attained temperature and the holding time at that temperature. This can be represented mathematically by:

$$
F_{T}(T, t)=F_{A} \eta_{T}(T, t)
$$

in which $F_{T}(T, t)$ is the tensile or shear capacity of the bolt at a certain temperature, $T$, and after specific time, $t, F_{A}$ is the design tension or shear resistance of the bolt at ambient temperature, and $\eta_{T}(T, t)$ is the bolt strength reduction value at a certain temperature, $T$, and after specific time, $t$.

Most studies in the literature adopt a similar holding time ranging between 15 and 20 minutes. Due to the limited availablity of data featuring the effect of holding time on the strength reduction factor, it is assumed that the reduction factors are independent of the holding time, similar to what is currently adopted by the international regulations [22, 23], thus:

$$
F_{T}(T)=F_{A} \eta_{T}(T)
$$


The experimental data was partitioned into three intervals based on temperature $\left(325^{\circ} \mathrm{C}\right.$, $600^{\circ} \mathrm{C}$ and $900^{\circ} \mathrm{C}$ ). The strength reduction values for the temperature ranges were derived by applying a suitable geometrical equation for the lowest recorded values within these intervals as follows:

$$
\begin{array}{lr}
\eta_{T}=-34.64 x 10^{-5} \mathrm{~T}+1.0069 & 20^{\circ} \mathrm{C} \leq \mathrm{T} \leq 325^{\circ} \mathrm{C} \\
\eta_{T}=-275.53 x 10^{-5} \mathrm{~T}+1.7898 & 325^{\circ} \mathrm{C} \leq \mathrm{T} \leq 600^{\circ} \mathrm{C} \\
\eta_{T}=5 e^{-0.006 T} & 600^{\circ} \mathrm{C} \leq \mathrm{T} \leq 900^{\circ} \mathrm{C} \\
\eta_{T}=-22.583 x 10^{-5} \mathrm{~T}+0.22583 & 900^{\circ} \mathrm{C} \leq \mathrm{T} \leq 1000^{\circ} \mathrm{C}
\end{array}
$$

Fig. 10 compares the proposed and codified reduction factors for high strength bolts. The proposed equations can be used to obtain reduced values of tensile and shear strength for high strength bolts at elevated temperatures. They also provide a conservative estimate the residual strength of high strength bolts after a fire (see section 6.4). Parameters affecting stripping failure are not defined explicitly in the literature, but as indicated in this study, warrant detailed investigation.

$\mathrm{Hu}$ et al. [15] provide curve fitting equations to predict the strength reduction factors for stainless steel bolts at elevated temperature. These equations are suitable for the current published experimental work. However, The authors believe that further tests are required to consider different modes of failure before exploiting these equations.

\section{Conclusions}

The behaviour of high strength and stainless steel bolt assemblies at elevated temperatures has been reviewed and presented. Whilst the behaviour and strength of these bolt assemblies at ambient temperatures now constitute a substantial body of research with most key param- 
eters and phenomena identified and understood, this study has shown that insufficient work has been conducted to develop reliable design guidance at elevated temperatures. The absence of consistent testing procedures for bolt assemblies at elevated temperatures, combined with the significant differences noted in the test parameters used by different researchers has resulted in a high degree of scatter in the experimental results and correspondingly, the strength reduction factors.

The conservatism of the codified strength reduction factors in European and the US standards during and after a fire has been discussed and compared with the experimental tests found in the literature. It is concluded that the codified reduction factors require updating as they may be non-conservative for high strength and stainless steel bolt assemblies, particularly in the highest temperature ranges. Accordingly, a preliminary equation for highstrength steel bolts was derived based on the existing experimental data using curve fitting methods.

In order to explain some of the observations of high strength and stainless steel bolt assemblies at elevated temperatures, basic insights into the role of phase transformation and metallurgical failure have been presented. Compared with stainless steel bolt assemblies, high strength bolts are more susceptible to failures that result from temperature-induced metallurgical transformations at the microstructure level. The fire performance of stainless steel bolt assemblies is superior to that of high strength bolt assemblies. This is due to the stability of its microstructure across the full practical temperature range of a fire. Despite this, very few published studies considering stainless steel bolts at elevated temperature exist in the literature.

\section{Acknowledgements}

This project is funded by a University of Manchester Dean's Award Scholarship, whose sponsorship is gratefully acknowledged. Dr. Jonathan Gosaye Fida Kaba is duly acknowledged. 


\section{References}

[1] CEN, "BS EN 1993-1-2:1995 - Eurocode 3: Design of Steel Structures - Part 1-2: General Rules - Structural Fire Design," Eurocode 3, 1995.

[2] C. G. Bailey, T. Lennon, and D. B. Moore, "The behaviour of full-scale steel-framed buildings subjected to compartment fires," Structural Engineer, vol. 77, no. 8, pp. 15-21, 1999.

[3] F. Wald, M. Chladná, D. Moore, A. Santiago, and T. Lennon, "The Temperature Distribution in a Full-Scale Steel Framed Builing Subject to a Natural Fire," Steel and Composite Structures, vol. 6, no. 2, p. 159, 2006.

[4] R. Barrett, "Fastener design manual," NASA Reference Publication 1228, 1990.

[5] Maritimer, "The fastener problem (part1)," Anti-Corrosion Methods and Materials, vol. 15, no. 7, p. 17, 1968.

[6] Maritimer, "The fastener problem (part2)," Anti-Corrosion Methods and Materials, vol. 15, no. 8, pp. 8-9, 1968.

[7] L. Bull, E. Palmiere, R. Thackray, I. Burgess, and B. Davison, "Tensile behaviour of galvanised grade 8.8 bolt assemblies in fire," Journal of Structural Fire Engineering, vol. 6, no. 3, pp. 197-212, 2015.

[8] S. G. Fan, G. P. Shu, C. S. Huo, C. L. Liu, and Y. L. Tao, "Research on performance of high-strength bolted connection in fire and after fire," IES Journal Part A: Civil and Structural Engineering, vol. 6, no. 2, pp. 135-149, 2013.

[9] F. González and J. Lange, "Behaviour of galvanized high strength grade 10.9 bolts under fire conditions," in Sixth International Conference Structure in Fire (SiF '10), 2009.

[10] Y. Hu, J. B. Davison, I. W. Burgess, and R. J. Plank, "Comparative study of the behaviour of BS 4190 and BS EN ISO 4014 bolts in fire," Proceedings of the 3rd Inter- 
national Conference on Steel and Composite Structures, ICSCS07 - Steel and Composite Structures, pp. 587-592, 2007.

[11] B. R. Kirby, "The Behaviour of High-strength Grade 8.8," Journal of Constructional Steel Research, vol. 33, pp. 3-38, 1995.

[12] V. Kodur, S. Kand, and Wasim Khali, "Effect of temperature on thermal and mechanical properties of high strength steel A325 and A490 bolts," Journal of Materials in Civil Engineering, vol. 24, no. June, pp. 765-774, 2012.

[13] J. Lange and F. González, "Behavior of High-Strength Grade 10.9 Bolts under Fire Conditions," Struct. Eng. Int., vol. 22, no. 4, pp. 470-475, 2012.

[14] R. M. Peixoto, M. S. Seif, and L. C. Vieira, "Double-shear tests of high-strength structural bolts at elevated temperatures," Fire Safety Journal, vol. 94, no. September, pp. 8-21, 2017.

[15] Y. Hu, C. B. Yang, L. H. Teh, and Y. B. Yang, "Reduction factors for stainless steel bolts at elevated temperatures," Journal of Constructional Steel Research, vol. 148, pp. 198-205, 2018.

[16] N. Baddoo, E. N. Moreno, B. Zhao, C. Renaud, A. Montanari, G. Zilli, J. Säynäjäkangas, P. S. T. Ala-Outinen, A. H. O. Bahr, F. Kettner, B. U. Claeys, and J., Stainless steel in fire. European Communities, 2009.

[17] G.-B. Lou, S. Yu, R. Wang, and G.-Q. Li, "Mechanical properties of high-strength bolts after fire," Proceedings of the Institution of Civil Engineers - Structures and Buildings, vol. 165, no. 7, pp. 373-383, 2012.

[18] J. Lange and A. Kawohl, "Tension-shear interaction of high-strength bolts during and after fire," Steel Construction, vol. 12, no. 2, pp. 124-134, 2019.

[19] K. C. Yang, R. J. Hsu, and Y. J. Chen, "Shear strength of high-strength bolts at elevated temperature," Construction and Building Materials, vol. 25, no. 8, pp. 3656-3660, 2011. 
[20] F. Hanus, G. Zilli, and J. M. Franssen, "Behaviour of Grade 8.8 bolts under natural fire conditions-Tests and model," Journal of Constructional Steel Research, vol. 67, no. 8, pp. 1292-1298, 2011.

[21] CEN, "BS EN 1993-1-4:2006 - Eurocode 3 - Design of steel structures - Part 1-4: General rules - Supplementary rules for stainless steels," Eurocode 3, 2006.

[22] CEN, "BS EN 1993-1-8:2005 - Eurocode 3: Design of steel structures - Part 1-8: Design of joints," Eurocode 3, 2005.

[23] AISC 360-16, "Specification for Structural Steel Buildings ANSI/AISC 360-16," An American National Standard, 2016.

[24] Y. Hu, S. L. Tang, A. K. George, Z. Tao, X. Q. Wang, and H. T. Thai, "Behaviour of stainless steel bolts after exposure to elevated temperatures," Journal of Constructional Steel Research, vol. 157, pp. 371-385, 2019.

[25] BSI, "BSI 4190:2014 - ISO metric black hexagon bolts, screws and nuts - Specification," BSI, London, UK, 2014.

[26] BSI, "BS EN ISO 4014:2011 - Hexagon head bolts - Product grades A and B," BSI, London, UK, 2011.

[27] R. M. Lawson and G. M. Newman, Fire Resistant Design of Steel Structures: A Handbook to BS 5950. Steel Construction Institute, 1990.

[28] Architectural Institute of Japan, Recommendation for fire resistant design of steel structures. 1999.

[29] BSI, "BS EN ISO 3506-1:2009 - Mechanical Properties of Corrosion-Resistant Stainless Steel Fasteners - Part 1- Bolts, Screws and Studs," BSI, London, UK, 2009.

[30] BS EN ISO 898-1, "Mechanical properties of fasteners made of carbon steel and alloy steel Part 1: Bolts, screws and studs with specified property classes - Coarse thread and fine pitch thread," 2013. 
[31] ASTM A325-03, "Standard Specification for Structural Bolts, Steel, Heat Treated 830 MPa Minimum Tensile Strength ( Metric )," ASTM International, 2003.

[32] ASTM A490-04, Standard Specification for Structural Bolts, Alloy Steel, Heat Treated, 150 ksi Minimum Tensile Strength. 2004.

[33] ASTM F593, "F593-Standard Specification for Stainless Steel Bolts," ASTM International, 2002.

[34] BSI, "BS EN 10269:2013 - Steels and nickel alloys for fasteners with specified elevated and/or low temperature properties," BSI, London, UK, 2013.

[35] ASTM-A193, "Standard specification for alloy-steel and stainless steel bolting for high temperature or high pressure service and other special purpose applications," ASTM International, 2010.

[36] BSI, "BS EN 1515-1:2000 - Flanges and their joints-Bolting - Part 1: Selection of bolting," BSI, London, UK, 2006.

[37] Y. Hu, L. Shen, S. Nie, B. Yang, and W. Sha, "FE simulation and experimental tests of high-strength structural bolts under tension," Journal of Constructional Steel Research, vol. 126, pp. 174-186, 2016.

[38] X. Wang, C. Hu, , and H. Chen, "Experimental research of ultimate bearing capacity of high-strength bolt at high temperature," Steel Construction, vol. 20, no. (3), pp. 89-91, 2005.

[39] L. S. Silva Da and A. Santiago, "Behaviour of steel joints under fire loading," Steel and Composite Structures, vol. 5, no. 6, pp. 485-513, 2005.

[40] K. S. Al-Jabri, J. B. Davison, and I. W. Burgess, "Behaviour of steel joints under fire loading," Fire Safety Journal, vol. 43, no. 1, pp. 50-62, 2008. 
[41] I. Burgess, J. B. Davison, G. Dong, and S. S. Huang, "The role of connections in the response of steel frames to fire," Structural Engineering International: Journal of the International Association for Bridge and Structural Engineering (IABSE), vol. 22, no. 4, pp. 449-461, 2012.

[42] H. X. Yu and J. Y. R. Liew, "Considering Catenary Action in Designing End-restrained Steel Beams in Fire," Advances in Structural Engineering, vol. 8, no. 3, pp. 309-324, 2005.

[43] M. Wang and P. Wang, "Strategies to increase the robustness of endplate beam-column connections in fire," Journal of Constructional Steel Research, vol. 80, pp. 109-120, 2013.

[44] X. H. Dai, Y. C. Wang, and C. G. Bailey, "Numerical modelling of structural fire behaviour of restrained steel beam-column assemblies using typical joint types," Engineering Structures, vol. 32, no. 8, pp. 2337-2351, 2010.

[45] Y. C. Wang, X. H. Dai, and C. G. Bailey, "An experimental study of relative structural fire behaviour and robustness of different types of steel joint in restrained steel frames," Journal of Constructional Steel Research, vol. 67, no. 7, pp. 1149-1163, 2011.

[46] E. M. Alexander, "Analysis and Design of Threaded Assemblies," SAE Technical Paper 770420, pp. 1838-1852, 1977.

[47] ISO 898-2, Mechanical properties of fasteners made of carbon steel and alloy steel Part 2 : Nuts with specified property classes - Coarse thread and fine pitch thread. Switzerland: ISO, 2012.

[48] H. Fransplass, M. Langseth, and O. S. Hopperstad, "Numerical study of the tensile behaviour of threaded steel fasteners at elevated rates of strain," International Journal of Impact Engineering, vol. 54, pp. 19-30, 2013. 
[49] E. L. Grimsmo, A. Aalberg, M. Langseth, and A. H. Clausen, "Failure modes of bolt and nut assemblies under tensile loading," Journal of Constructional Steel Research, vol. 126, pp. 15-25, 2016.

[50] E. L. Grimsmo, A. Aalberg, M. Langseth, and A. H. Clausen, "How placement of nut determines failure mode of bolt-and-nut assemblies," Steel Construction, vol. 10, no. 3, pp. 241-247, 2017.

[51] E. C. Fischer, A. H. Varma, and Q. Zhu, "Experimental Evaluation of Single-Bolted Lap Joints at Elevated Temperatures," Journal of Structural Engineering, vol. 144, no. 1, p. $04017176,2018$.

[52] M. Sarraj, The behaviour of steel fin plate connections in fire. PhD thesis, 2007.

[53] H. Yu, I. Burgessa, J. Davisona, and R. Plankb, "Experimental investigation of the behaviour of fin plate connections in fire," Journal of Constructional Steel Research, vol. 65 , no. 3, pp. 723-736, 2009.

[54] C. W. Lee, D. W. Fan, I. R. Sohn, S. J. Lee, and B. C. De Cooman, "Liquid-metalinduced embrittlement of Zn-coated hot stamping steel," Metallurgical and Materials Transactions A: Physical Metallurgy and Materials Science, vol. 43, no. 13, pp. 5122$5127,2012$.

[55] L. Canale, R. Mesquita, and G. Totten, Failure Analysis of Heat Treated Steel Components. ASM International, 2008.

[56] W. D. Callister and D. G. Rethwisch, Materials Science and Engineering. New York: John wiley \& sons, 2007.

[57] H. G. NELSON, "Hydrogen embrittlement," Treatise on Materials Science 83 Technology, vol. 25, pp. 299-335, 1983.

[58] B. Bøgner, G. Rørvik, and L. Marken, "Bolt failures - Case histories from the Norwegian petroleum industry," Microsc Microanal, vol. 11, no. Suppl 2, pp. 1604-1605, 2005. 
[59] A. H. Buchanan and A. K. Abu, Structural Design for Fire Safety. John Wiley \& Sons, Ltd, 2017.

[60] G. Hu and M. D. Engelhardt, "Investigations on the Behavior of Steel Single Plate Beam End Framing Connections in Fire," Journal of Structural Fire Engineering, vol. 2, no. 3, pp. 195-204, 2011.

[61] A. Santiago, L. S. Da Silva, P. V. Real, G. Vaz, and A. G. Lopes, "Experimental evaluation of the influence of connection typology on the behavior of steel structures under fire," Engineering Journal, vol. 46, no. 2, pp. 81-98, 2009.

[62] S. Spyrou, J. B. Davison, I. W. Burgess, and R. J. Plank, "Experimental and analytical investigation of the tension zone components within a steel joint at elevated temperatures," Journal of Constructional Steel Research, vol. 60, no. 6, pp. 841-865, 2004.

[63] H. Yu, I. W. Burgess, J. B. Davison, and R. J. Plank, "Experimental and Numerical Investigations of the Behavior of Flush End Plate Connections at Elevated Temperatures," Journal of Structural Engineering, vol. 137, no. 1, pp. 80-87, 2011.

[64] T. Hirashima, Y. Esaki, and S. Ando, "Load-deformation behavior of bolted doublesplice friction joints at elevated temperature," in 8th International Conference on Structures in Fire, Shanghai, China, 2014.

[65] H. Yu, I. Burgess, and B. Davison, "Experimental Investigation of the Robustness of Fin Plate Connections in Fire," in ICASS, vol. 1, pp. 722-727, 2007.

[66] C. L. Davis and J. E. King, "Effect of cooling rate on intercritically reheated microstructure and toughness in high strength low alloy steel," Materials Science and Technology, vol. 9, no. 1, pp. 8-15, 1993.

[67] H. K. D. H. Bhadeshia and R. Honeycombe, Steels Microstructure and Properties. Elsevier Ltd, 3rd ed., 2006.

[68] R. Haimbaugh, Practical induction heat treating. ASM international, 2015. 
[69] J. L. Dossett and H. E. Boyer, Practical Heat Treating. ASM International, 2006.

[70] A. P. Mouritz, "Failure Mechanisms under Different of Mild Steel Bolts Tensile Loading Rates," Int. J. Impact Engng, vol. 15, no. 3, pp. 311-324, 1994.

[71] M. A. Meyers and K. K. Chawla, Mechanical behavior of materials. Cambridge University Press, New York, 2009.

[72] T. Furuhara, K. Kobayashi, and T. Maki, "Control of Cementite Precipitation in Lath Martensite by Rapid Heating and Tempering," ISIJ International, vol. 44, no. 11, pp. 1937-1944, 2008.

[73] V. Kodur, M. Yahyai, A. Rezaeian, M. Eslami, and A. Poormohamadi, "Residual mechanical properties of high strength steel bolts subjected to heating-cooling cycle," Journal of Constructional Steel Research, vol. 131, pp. 122-131, 2017.

[74] X. Qiang, F. Bijlaard, and H. Kolstein, "Dependence of mechanical properties of high strength steel S690 on elevated temperatures," Construction and Building Materials, vol. 30, pp. 73-79, 2012.

[75] J. Chen, B. Young, and B. Uy, "Behavior of High Strength Structural Steel at Elevated Temperatures," Journal of Structural Engineering, vol. 132, no. 12, pp. 1948-1954, 2006.

[76] M. A. Shaheen, K. D. Tsavdaridis, and E. Salem, "Effect of grout properties on shear strength of column base connections: FEA and analytical approach," Engineering Structures, vol. 152, pp. 307-319, 2017.

[77] L. Simões Da Silva, A. Santiago, and P. Vila Real, "A component model for the behaviour of steel joints at elevated temperatures," Journal of Constructional Steel Research, vol. 57, no. 11, pp. 1169-1195, 2001.

[78] CEN, "BS EN 1993-1-2:2005 - Eurocode 3: Design of Steel Structures - Part 1-2: General Rules - Structural Fire Design," Eurocode 3, 2005. 
[79] ASCE, "Structural fire protection," American Society of Civil Engineers, ASCE Committe on Fire Protection, Structural Division, New York, 1992. 